Portland State University

PDXScholar

7-31-1967

\title{
Die Moabiter Sonette; letzte Gedichte und Gedanken Albrecht Haushofers
}

Richard S. Kemmler

Portland State University

Follow this and additional works at: https://pdxscholar.library.pdx.edu/open_access_etds

Part of the German Literature Commons

Let us know how access to this document benefits you.

\section{Recommended Citation}

Kemmler, Richard S., "Die Moabiter Sonette; letzte Gedichte und Gedanken Albrecht Haushofers" (1967). Dissertations and Theses. Paper 595.

https://doi.org/10.15760/etd.595

This Thesis is brought to you for free and open access. It has been accepted for inclusion in Dissertations and Theses by an authorized administrator of PDXScholar. Please contact us if we can make this document more accessible: pdxscholar@pdx.edu. 
AN ABSTRACT OF THE THESIS OF

Richard S. Kemmler for the Master of Arts in German

Date thesis is presented: July 31, 1967

TITLE: DIE MOABITER SONETTE LETZTE GEDICHTE

UND GEDANKEN ALBRECHT HAUSHOFERS

Abstract approved:

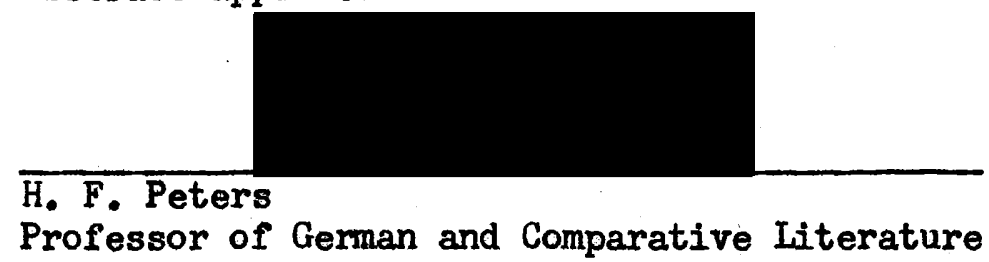

Albrecht Haushofer wrote the Moabiter Sonette while confined in a Nazi prison in Berlin during the last months of World War II. His arrest resulted from his indirect involvement in the resistance movement which culminated with the July 20, 1944 attempt on Hitler's life.

From 1933 to his arrest Haushofer was directly and indirectly involved in work aimed at overthrowing Hitler's regime and forming a new government. Through his father's friend, Rudolf Heß, Haushofer was 'inofficially' appointed in 1933 to the Foreign Office under Ribbentrop. His effect on German government policies was however nil. In 1937 he left the Foreign Office and devoted himself to his professorial duties at the University of Berlin. His activities with the resistance movement under the leadership of Johannes Popitz began during these years. 
The failure of the July, 1944 coup led to the immediate arrest of all those who were in the least suspected. Haushofer fled to Bavaria where he successfully avoided detection and arrest until early December, 1944. He was murdered on April 23, 1945 by the Nazis.

To a keen observer like Albrecht Haushofer the fact that Germany was doomed was a foregone conclusion and with his arrest he also realized that the chances of his own survival were slim. Alone in his prison cell he reflected on his life, his family and friends, his travels and his homeland. He brought these reflections to poetic expression in the Moabiter Sonette. They represent a poetic monologue, a poetic diary whose entries recall a variety of personal experiences, memories and ideas.

For the purpose of this investigation, the sonnets are divided into categories. In one category the sonnets reflect memories of family, friends, of homeland and far-reaching travels. His deeply felt despair over the total destruction of Germany, her lands as well as her tradition, constitutes a second category. Sonnets referring to his fellow prisoners as well as to those countless innocent people who suffered under the tyrannical, destructive hands of the Nazi regime are also included in the second grouping. His passionate longing for freedom forms yet another group. But most important of all are those sonnets which demonstrate the poet's fundamental personal evolution, in which he comes to a new and deeper understanding of himself, and an eventual surmounting of his fears of death. From a point of suicide he rises, despite recurring despair, to a newly discovered inner peace and contentment in the face of certain death. It is this 'becoming' which speaks most 
loudly and most clearly out of the lines of the Moabiter Sonette.

This thesis traces the historical events which lead up to Haushofer's arrest and develops, through the sonnets as well as Haushofer's dramatic works, his 'Weltanschauung.' With this basic background the sonnets are interpreted from a 'biographical' standpoint. Apart from this historical, philosophical and biographical interpretation, the sonnets are investigated in regard to poetic form. A discussion is undertaken in order to ascertain why the poet chose the sonnet form as a means of expression. A comparison is made with earlier unpublished lyrical works in an attempt to underscore the sonnets from a standpoint of form and content and to trace Haushofer's development as a poet. The final chapters of the thesis discuss Haushofer as a political poet and summarize my own thoughts and the thoughts of numerous critics regarding the worth of the sonnets as poetry and as a document of the so oft forgotten spirit which moved men like Haushofer to risk their lives for the belief that justice and freedom could and should prevail. 


\section{DIE MOABITER SONETTE}

\section{LETZTE GEDICHTE UND GEDANKEN ALBRECHT HAUSHOFERS}

\section{by}

RICHARD S. KEMMIER

\section{A THESIS}

Eresented to the Department of Foreign Languages. and the Graduate Council of Portland State College in partial fulfillment of the requirements for the degree of Master of Arts in German June 1968 
APPROVED :

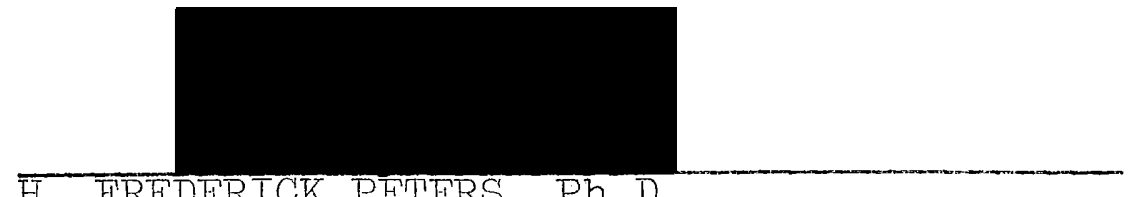

F. FREDERICK PETERS, Ph.D.

Thesis Advisor

H. FREDERICK PETERS, Ph.D.

Administrative Officer

Department of Foreign Ianguages

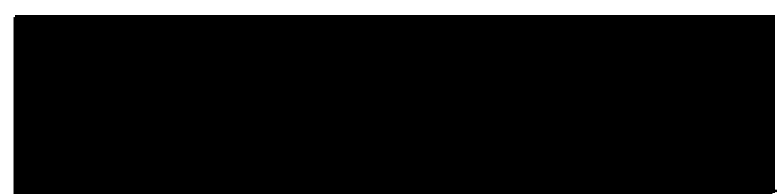

FREDERICK J. COX,Ph.D.

Dean of Graduate School

Date thesis is presented: July 31, 1967 


\section{Tnha] tsangabe}

I. Einleitung. . . . . . . . . 1

II. Der Weg nach Moabit: Ein kurzer Überblick über das Leben Albrecht Haushofers 1933 - 1945. . • . . . 5

III. Die Weltanschaung des Dichters: in seinen Werken widergespiegelt. . . 19

IV. Themen der Moabiter Sonette . • • .35

1. Erinnerungen an sein verganges Leben • • • • • • . 37

2. Finige Gedanken aus einer Gefängniszelle. • • . • • . . 57

3. Selbstüberwindung und innere Wandlung des Dichters . . . . .63

V. Die Form der Moabiter Sonette und. einige Besonderheiten des Stiles. • .71

VI. Warum Sonette?. . . . . . . .78

VII. Ein Vergleich der Sonette mit friheren Gedichten. . . . . . . 88

VIII. Albrecht Haushofer als Politischer Dichter . . . . . . . . .97

IX. Der dichterische und historische Wert der Noabiter Sonette . . . 103

X. Bibliographie . . . . . 109 


\section{I: EINIEITUNNG}

Die Moabiter Sonette sind "die letzten Gedichte Albrecht Haushofers, der sein Ieben opferte, weil er ein Mensch war, [der $\overrightarrow{\underline{r}}$ die Freiheit über sein Ieben stellte. Aus der Hand des Toten empfangen, legen sie Zeugnis ab für den Geist, der ihn bewegte."1

Albrecht Haushofer schrieb die 80 sonette $^{2}$ der Moabiter Sonette während der letzten Tage seines Lebens im Gefängnis in Berlin. Drei Wochen nach Haushofers Emordung am 23. April 1945 durch die Gestapo fand Haushofers Bruder die Leiche des Dichters auf einem Trïmerhaufen nicht weit vom Gefängnis. In der Hand des Toten befand sich ein Manuskript, das den Titel Moabiter Sonette trug.

In dem Menschen Albrecht Faushofer vereinigten sich mehrere Talente. Er war sowohl Politiker, Staatsmann, wissenschafter, Iehrer, als auch Dichter. Jede dieser Fähigkeiten strebte nach Ausdruck, und jede fand ihn.

1Titelblatt. Noabiter Sonette. (Berlin: Lothar Blanvalet Verlag, 4. Auflage, 1953.)

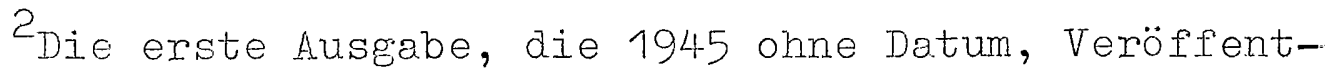
lichungsort oder Verlagsname mit Sanktion der amerikanischen Okkupationsarmee erschien, schließt alle 80 Sonette, die der Dichter schrieb, ein. In der späteren Ausgabe vom Jahre 1946 vom Lothar Blanvalet Verlag in Berlin wurde das Sonett "Bombenregen" ausgelassen. Da die erste Ausgabe wenig bekannt ist, spricht man meistens von den 79 Moabiter Sonetten. 
Er glaubte, daß Künstler und Gelehrter mit dem Politiker zusammenarbeiten müßten, und in ihm trafen mit einer vereinigung der Zielsetzung alle drei Tätigkeiten zusammen. Durch seine drei Römerdramen, Scipio, Sulla und Augustus, die im ersten Jahre der nationalsozialistischen Herrschaft entstanden und auch erschienen, warnte er vor der Katastrophe, der Deutschland entgegenging. Folgende Worte schrieb er in dem im Jahre 1933 erschienenen Scipio:

Liegt alles, was von unsern Ahnèn kommt. Ich habe es noch ein letztes Mal gesammelt, Als Ordnung mir und anderen gesetzt. $\therefore$...was nach uns kommt, Mißachtet Maß und Wissen und Gesetz, Und sucht nach neuem Weg in neuer Wirrnis. 3

In seiner Tätigkeit als Professor versuchte er seinen Schülern die wahren Ansichten und Ziele des Nationalsozialismus zu enthüllen:

Er saß unter [seinen Schülern] und sprach davon, was hinter den Kulissen des NaziRegimes geschah und versuchte, den Vorgang in seinem ganzen politischen Zusammenhang $\mathrm{zu}$ verdeutlichen. 4

Haushofer benützte auch die beschränkte Möglichkeit, als inoffizieller Angestellter des auswärtigen Amtes, vor den kommenden Ereignissen zu warnen:

Kassandro hat man mich im Amt genannt,

3 Albrecht Haushofer. Scipio, ein Schauspiel in fünf Akten. (Berlin: Propyläen Verlag, 1934) S. $21 \overline{6}$.

${ }^{4}$ Rainer Hildebrandt. Wir sind die Ietzten. Aus dem Leben des Widerstandskämpfers Al brecht Haushofer und seiner Freunde. (Neuwied/Berlin: Nichael Verlag, $1949,5.50$. 
weil ich, der Seherin von Troja gleich, die ganze Todesnot von Volk und Reich durch bittre Jahre schon vorausgekannt. 5

"Das rein Menschliche, Spontane in ihm, das eingepreßt zwischen der Festigkeit seines tiefsten Wesens und der Nüchternheit seines Verstands oft schwer zur Eußerung kam, fand einen Weg in künstlerischem Gestalten. Im Iyrischen Gedicht durfte das reine Gefühl strömen, und im politischen Drama wurde das, was ihn bewegte, Bild, Handlung und wort." 6 Während der schweren und ungewissen wochen seiner Gefangenschaft hatte Albrecht Haushofer Zeit, sich seiner Familie, seiner Heimat, seiner Freunde und der Frfahrungen seiner zahlreichen Reisen zu erinnern und über seine Gefühle und Einstellung zum Ieben im allgemeinen nachzudenken.

Diese Gedanken brachte er in den Moabiter Sonetten zum Ausdruck. Man spürt in den Sonetten eine Wahrheit und eine Klarheit, die nur von einem Menschen kommen konnte, der keine Gründe mehr hatte, seine Gerühle zu verbergen. So wie Albrecht Haushofers Persönlichkeit durch die ausgedehnten Reisen und Auseinandersetzung mit der Geschichte eine entscheidende Frägung erfuhr, so liefern auch Reiseeindrücke, Landschaftserlebnisse und historische Episoden

\footnotetext{
5 Albrecht Haushofer. Noabiter Sonette. (Berlin: Jothar Blanvalet Verlag, 1953, 4. Auflage), S. 69.

${ }^{6}$ Carl F. von Weizsäcker. "Albrecht Haushofer und die Jugend," in In Wemoriam Albrecht Haushofer. (Hexausgegeben von Rolf Italiaander). (Hamburg: Verlag Friedrich Oetinger, 1948). S. 23.
} 
4

die Mehrzahl der stofflichen Elemente für séine Lyrik. Jedoch diese realen Landschaftseindrücke oder Geschebnisse sind gleichsam nur ein stück seltsam schillernden Glases, durch das der Dichter die Tiefen menschlicher Einsamkeit, seelischer Problematik oder irdischer Vergänglichkeit hindurchspiegelt.

Der Leser spürt des Dichters Menschenverständnis und Mitgefühl. Die Versen dieser Sonette zeigen Haushofers Trauer über den Untergang seines Vaterlandes; aber äußern sie auch seine Überzeugung, daß aus den Ruinen eine neue Welt wachsen würde.

All das zusammen schaffte eine Sammlung Gedichte, die beute als Zeugnis des Geistes gelten, der in diesen tragischen Jahren einige Menschen bewegte, nicht nur ihre Fieimat und die Sicherheit ihrer Familie aufzugeben, sondern ihr eigenes Ieben zu opfern, weil sie die Freiheit und das Recht schätzten und an die Foffnung glaubten, daß aus Bösem wieder Gutes entstehen würde. 
II. DER WEG NACH WOABIT

Der Weg, der schließlich zu Haushofers Verhaftung, den Moabiter Sonetten und seinem Tod führte, begann wenn man überhaupt einen Anfangspunkt nennen kann schon 1933, im ersten Jahr der Herrschaft Hitlers, als er von dem Freund seines Vaters Rudolf Heß ganz inoffiziell als außenpolitischer Berater herangezogen wurde.

Rudolf HeB schätzte und bewunderte Albrecht Haushofer sowie dessen Vater sehr. Obwohl Haushofer "Judenstämmling" war und wie Rainer Hildebrandt schreibt, einige aus der Partei ihn "zur strecke bringen" wollten, gelang es Heß, über ihn und die ganze Haushofer Familie ein "Tabu" zu verhängen.

Zu dieser Zeit sollte Ribbentrop Außenminister werden. "Heß hatte wenig. Vertrauen zu dem ehemaligen Sektreisenden, der in Bälde den Posten von Neurath übernehmen sollte." ${ }^{1}$ Daher wollte er unbedingt, daß Albrecht Haushofer, gewissermaßen als "Instruktor" an die seite von Ribbentrop gestellt wïrde.

Haushofer glaube, Heß sei der bester Vermittler, durch den seine Gedanken zur Spitze der Partei kommen konnten. Hildebrandt berichtet aber, seine Einwirkung auf Hitler und seine Politik war gering. Mit Hitler persönlich ins Gespräch zu kommen, gelang ihm nur selten, 
und wenn Haushofer seine eigenen Auffassungen darzustellen begann, führte Eitler häufig das Gespräch auf die Berichtsform zurück.

Durch seine Beziehungen 'zum Auswärtigen Amt lernte Haushofer in diesen Jahren einflußreiche Engländer kenner. Seine ausgezeichnete Beherrschung der englischen Sprache, seine Art, deutsche Probleme verständlich zu machen, und seine hervorragende Kenntnis der Geschichte Englands, erweckten in England Sympathie und großes Interesse. Die Beziehungen, die er während dieser Zeit anknüpfte, sollten ihm später nützlich sein, als er in den Kreis der Widerstandsbewegung eintrat.

Ribbentrop war nicht blind für Haushofers Feindschaft gegen den Nationalsozialismus und tat sein Möglichstes, Haushofer bei Hitler zu diskreditieren, Heß und Weidemann jedoch sprachen sich sehr positiv über Haushofer aus. während dieser Zeit entstand Haushofers zweites Römerdrama Sulla (1936). Die Angst, in der er während dieser Zeit lebte, daß Hitler ihn gegen seinen willen zum Außenminister ernennen könnte, schilderte er in diesem Drama aurch die Figur des Zosias, eines weisen griechischen Lehrers. Zosias wurde von dem römischen Diktator Sulla gezwungen, ein hohes Amt zu übernehmen.

"Und Ihr verlangt, daß ich der Jugend Roms, Aus meinern Ieben, nicht aus meinern Wissen, Das geben soll, was sie für Euren Dienst 
Zugleich befähigt und gefügig macht."2

Utber diese Möglichkeit schreibt Rainer Hildebrandt:

Ich habe mit Albrecht Haushofer nie darüber gesprochen, ob er damals den Posten eines Außenministers...übernommen hätte. Sein Ehrgeiz hätte ihn zuletzt dazu getrieben, nach einer schuldigmachenden Stellung unter einer Regierung zu streben, deren Katastrophen Ende er jedem seiner nahen Freunde bewies. Dieser Mann, den man sich als Hassenden nicht vorstellen konnte, zeigte eine so abgrundtiefe Feindschaft, daß mancher spürte, sie würde sein Schicksal werden. Und doch glaube ich, daß Haushofer den Außenministerposten aus der Erwartung, Lawinenrutsche verhindern zu können, übernommen hätte. 3

$\mathrm{Zu}$ dieser Zeit fanden auch die Olympischen Spiele in Berlin statt. Später erinnerte sich der Dichter an diese "festlichen" Spiele, die vom Nationalsozialismus zur Verherrlichung seines Regimes miBbraucht wurden, und er verwendete sie als Thema dreier sonette. Der MiBbrauch des geheiligten olympischen Feuers wird für Haushofer zu einem Symbol des Weltbrandes, der zur Entstehungszeit dieser Gedichte schon manches Iand verzehrt hatte.

Vision der Fackel

Ein Mannesleib von Adel, Maß und Schwung vollendet eines Feuers Fackelzug, das man aus Griechenland nach Norden trug, als Licht olympischer Erinnerung.

In jenem Hain der Säulen und der Bäume, wo Götterzeugung durch die Zeiten webt, entsprang die Leuchte. Hüte sie, wer lebt

${ }^{2}$ Albrecht Haushofer. Sulla, Ein Schauspiel in

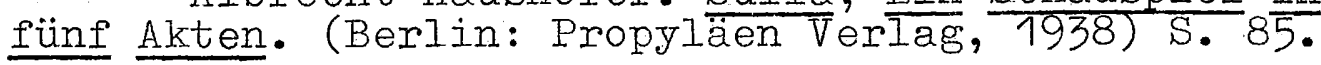
3 Hildebrandt, S. 52 . 
In jeder Leuchte zucken Flammenträume... Durch viele Länder nahm es seinen Lauf, das Feuer, das, in Griechenland entzündet, Jahrtausenden von Geist und Spiel gekündet zwingt ihr dem Feuer eine Knechtschaft auf? Es zischt und sprüht, wie man's in Banden hält. Die Fackel flackert. Lodern - wird die Welt. 4

Haushofer erkannte die Maske, die das echte Gesicht des "wiedergeborenen". Deutschlands verbarg und diese Erkenntnis äußert er in dem Sonett "Olympisches Fest." In diesem Gedicht benützte der Dichter das "hochgestrahlte Iicht" der olympischen Fackel und den lauten Glanz des Festes als Symbol für die Blinaheit und Torheit des deutschen Volkes. Geblendet von Torheit und Rausch des Augenblicks sah das Volk die Sterne nicht, die die schwarze Zukunft symbolisierten.

\section{Olympisches Fest}

Mit einem Dom von hochgestrahltem Iicht begannen sie das letzte ihrer Feste. Der Hochmut freute sich der stolzen Geste: Man sah vor lauter Glanz die Sterne nicht. Gelöst von aller Tage bunten Sorgen, bestaunte man der Jugend Marsch und Spiel, bewunderte der Grieclenfackel Ziel, im Leuchten dieses Kuppelscheins geborgen, Mich täuschte dieser helle Zauber nicht. Ich sah die Kräfte, die so milde schienen, dem grauenhaftesten der Kriege dienen.

Ich kannte wie die Maske das Gesicht.

Die sich zum Spielen Schar um Schar gereiht:

Die ganze Jugend ist dem Tod geweiht. 5

Im Sommer 1937 trat Haushofer eine mehrmonatige

\footnotetext{
${ }^{4}$ Haushofer, Moabiter Sonette, S. 35.

5 Ibid., S. 34.
} 
Informationsreise durch Ostasien an. Diese Reise hatte für jhn persönlich höchste Bedeutung. Eigentlich war ihm der Orient durch die vielen Erzählungen seines Vaters bekannt. Schon als Kind hatte die orientalische Philosophie und Lebensart auf ihn großen Einfluß. Aus der Quelle der morgenländischen Geschichte, Volkslegende und Philosophie nahm er den Stoff für mehrere Gedichte, unter anderem für das Thema seines dramatischen Gedichtes, Chinesische Iegende. Den Finfluß der stoischen Philosophie des Orients auf Haushofer sieht man klar in fölgenden Sonett. Seine eigene Wortwahl sagt am besten, wie er nach Hoffnung und Trost in einer philosophischen Religion des Orients gesucht hat.

\section{Om Mani Padme Hum}

Heut nacht war mir ein andres Bildnis nah: So mild und still, so friedevoll und fern wie ein Geschenk von einem andern Stern. Der große Buddha von Kamakura. Aus einem Hain von Kirschenblüten schaut er auf das Fischerdorf und bleibt gelassen, ob. Kinderlachen spielt in seinen Gassen, ob Weltenmeer darüber stürme braut.

Er kennt kein Zürnen, kein Verzweifeltsein, und lehrt nur eines: wie man sich versenke, den Einzelwillen in die Allheit lenke, die Seele lösend aus der Dinge Schein, will Buddha sie aus allem Ieiden heben -
dem Lotos fühl ich lächelnd ihn entschweben.

Sehr bald nach der Rückkehr aus dem Fernen Osten im Frühjahr 1938 wurde Haushofer politisch völlig ausgeschaltet. Teilweise wegen des Bruchs mit Ribbentrop 
und wahrscheinlich auch, weil er wuBte, daß seine Warnung nicht gehört und nicht beachtet werden würde, schied er aus dem Auswärtigen Amt aus.

Während dieser Jahre förderte Albrecht Haushofer auch seinen Beruf als Lehrer und Wissenschaftler. Im Jahre 1933 wurde er Dozent und Leiter des Geopolitischen Seminars der Berliner Hochschule für Politik. Nach dem Verlassen seiner aktiven politischen Tätigkeit, widmete er sich ganz seinen Schülern und seinen wissenschaftlichen Arbeiten. Hildebrandt, der damals einer seiner Schüler war, schrieb über den Lehrer Haushofer:

Schon damals möchte er geahnt haben, daß dieses nicht nur die gestaltendste äuBere, sondern auch die wichtigste innere station seines Lebens sein würde. Wohl war Kopf und Wille zum Wissenschaftler und Politiker berufen, aber der Mensch war zum Lehrer und Freund - das eine untrennbar von dem anderen - geboren.?

Mit dem Ausbruch des Krieges trat Haushofer neuerdings in das Auswärtige Amt ein. Dieses Mal arbeitete er in der Informationsabteilung, wobei er besonders für geographische und Volkstumsfragen herangezogen wurde.

Im Jahre 1940 schloß sich Albrecht Haushofer dem Kreis des Widerstands an. Durch seinen Bekannten, Karl Langbehn, lernte er das Haupt des Kreises, Johannes Popitz, den ehemaligen preußischen Finanzminister, kennen. Durch Popitzes Vermittlung kam Haushofer in den Personenkreis der Mittwochsgesellschaft. Zu dieser Gesellschaft gehörten 
etwa 15 Männer aus allen Geistesgebieten. Unter: ihnen waren: Dr. Carl-Friedrich Gördeler, ehemaliger Oberbürgermeister von Leipzig; der ehemalige Generaloberst Erwin von Witzleben; Generaloberst Iudwig Beck, der 1938 aus Protest gegen die Nationalsozialisten sein Amt niedergelegt hatte; Erwin Planck, Sohn des berühnten Physikers Max Planck; Ulrich von Hassel, einer der bedeutendsten deutschen Diplomaten; Peter Graf Yorck von Wartenburg und Fritz von der Schulenberg. ${ }^{8}$

Es war die Hoffnung dieser Männer, eine Verbindung zwischen den zivilen Widerstandskämpfern und dem Militär herzustellen und eine wirksame Verschwörung zu bilden, die nicht nur die nationalsozialistische Regierung stürzen, sondern eine neue Regierung formen sollte.

A.s Haushofer zu dieser Gruppe kam, war es sicher, daß das Hitler-Regime auf legalem Wege nicht mehr beseitigt werden konnte. "Alle Versuche, auf legale Weise mit dem Regime fertig zu werden, sind erschöpft. Jetzt kann uns nur noch der tote Hitler retten. Wir müssen handeln. Wir wissen nicht, was Gott zuläßt, aber wenn ein Volk so weit getrieben wird, hat es ein Recht zu jedem Mittel, das den Kerl erledigt, auch zum Attentat, "9 meinte Popitz schon 1938. Aber Verzweiflung, Komplikationen, Zögern, Pessimismus und mißlungene Vorbereitungen und Aktionsversuche hinderten die Verschwörung am Erfolg.

$$
\begin{aligned}
& { }^{8} \text { Ibid., S. } 92 \text { ff. } \\
& { }^{9} \text { Ibid., S. } 91 .
\end{aligned}
$$


Als Popitz Langbehn und Haushofer kennengelernt hatte, fühlte er, daß in diesen beiden Männern seine politischen Pläne neuen Inhalt gefunden hatten. Alle drei hatten persönliche Erfahrungen mit den höchsten Nazi-Fïhrern und kannten die innerste struktur der Partei. Sie erkannten, daß der Hauptteil ihrer Aktionsvorberejtungen nicht nur auf das Attentat auf Hitler gerichtet sein sollte, sondern daß sie sich auch bemühen mußten, möglichst viele wichtige schalthebel des viachtapparates schnell in die Fand zu bekommen.

Ulrich von Hassel war besonders aktiv auf der Suche nach englischen Verbindungen. Hassel und seine Kollegen hatten die Hoffnung, von England Unterstützung für die Widerstandsbewegung zu erhalten. Im Eebruar 1941 führte er über zwei Mittelsmänner mit England ein sehr wichtiges Friedensgespräch von der Schveiz aus. Albrecht Haushofer sollte als nächster Vertreter der Widerstandsbewegung die Verhandlungen fortsetzen.

Ende April 1941 reiste Haushofer in die Schweiz, um die Friedensgespräche weiterzuführen. Am 11. Mai 1941, dem Tag nach der Flucht von Heß nach England, traf Haushofer aus der Schweiz wieder in Berlin ein. Die Hoffnung auf weitere Friedensgespräche var nun völlig zerstört. Von Hassel schrieb in seinem Tagebuch:

Durch die Flucht von Heß ist nun jede Möglichkeit auf dem Wege Haushofers weiterzukommen, verschütet. Er sollte eigentlich nach einigen Wochen nochmal zu Burckhardt fahren, der inzwischen 
wieder Fühlung nehmen wollte, und wir wollten dann die gesammelten Eindrücke verwerten. Das ist nun vorbei."10

Diesen Männern, die mit ihm bereit waren, alles für ein besseres Deutschland zu riskieren, widmete Haushofer da.s Sonett "Gefihrten."

\section{Gefährten}

Als ich in dumpfes Träumen heut versank, sah ich die ganze Schar vorïberziehn:

Die Yorck und Moltke, Schulenburg, Schwerin, die Hassel, Popitz, Helferich und Planck nicht einer, der des eignen Vorteils dachte, nicht einer, der gefühlter Pflichten bar, in Glanz und Macht, in tödlicher Gefahr, nicht um des Kolkes Leben sorgend wachte. Den Weggefährten gilt ein langer Blick: Sie hatten alle Geist und Rang und Namen, die gleichen Ziels in diese Zelle kamen und ihrer aller wartet der strick. Es gibt wohl Zeiten, die der Irrsinn lenkt. Dann sind's die besten Köpfe, die man henkt. 11

Albrecht Haushofer sowie sein Vater hatten nicht aufgehört, Heß zu beweisen, daß der Krieg sein schnellstmöglichstes Ende finden müsse. Aber durch diese unerwartete und sinnlose Handlung von Heß war Haushofer vollkommen überrascht und verzweifelt. "Dieser motorisierte Parsifal will Hitler den Frieden bringen und bildet sich ein, er könne die Chruchill-Regierung umgehen und sich mit dem englischen König an den Verhandlungstisch setzen, "12

\footnotetext{
10 Ulrich von Hassel. Vom anderen Deutschland. Aus den nachgelassenen Tagebüchern 1938-1944. (Zürich und Freiburg: Atlantis Verlag, 1946) S. 205.

11 Haushofer, Moabiter Sonette, S. 31. 12 Hildebrandt, $\mathrm{S} .112$.
} 
sagte Haushofer zu seinem Freund Rainer Fildebrandt. Es war ihm unverständlich, daß nun, wo man schon so weit gekommen war, alles umsonst sein sollte, liit seinen Hoffnungen waren die aller seiner politischen Freunde begraben.

Wegen seiner langen und engen Beziehung zu HeB wurde Haushofer sofort verhaftet. "Albrecht Haushofer ist nach Auskunft seiner Haushëlterin in der Nacht nach dem Vorfall HeB' um zwei Uhr von zwei Herren abgeholt worden..."13 schrieb UIrich von Hassel über Haushofers Verhaftung. Kurz danach brach der RuBIandfeldzug aus, und damit schwand die Hoffnung der Männer der Verschwörung, daß England zu einem Verständigungsfrieden bereit sein wirde.

Während dieser ersten Haft schrieb Haushofer sein letztes vollendetes Drama, Die Makedonen. Als er die letzten Worte dieses Dramas niederschrieb, öffneten die wächter die Tür seiner zelle mit den worten:

"Herr Professor, Sie haben Thre Freiheit wieder." Haushofer lächelte. Dann aber brannte es ihm auf den Lippen zu sagen: "Jetzt gehe ich nur in das gröBere Gefängnis zurïck."

Wenige Tage nachdem Haushofer aus seiner Haft entlassen war, reiste er u seinen Eltern. Wieder fand er sich in seiner geljebten Iandschaft der bayerischen Berge, wo er "eigentlich nur...ganz 'zu Hause' war."15 Während dieses Spätsommers und Herbstes 1941 begann

13 von Hassel, S. 204.

14 Hildebrandt, S. 122 .

15 Ibid. S. 126. 
er sein grundlegendes wissenschaftliches Werk: Politische Geographie und Geopolitik. Er war noch nicht vierzig Jahre alt, als er dieses Werk anfing, und möglicherweise hat er geahnt, daß die Zeit, dieses Werk zu beenden, nur kurz sein werde.

Im Herbst 1941 war er wieder in Berlin; wo er sich mit seinem Unterricht und seiner wissenschaftlichen Arbeit beschäftigte. Er pflegte auch seine Beziehungen zu Fopitz und den anderen Männern der Widerstandsbewegung. Aber die GewiBheit, von der Gestapo beobachtet zu werden, beeinträchtigte seine Aktivität in diesem Kreis.

Eine Assistentin Haushofers, die mit einem SS-Mann verheiratet war, aber durch persönliche Erfahrungen eine Feindin des Regimes geworden war, wurde von dem GestapoGruppenführer: Mïller damit beauftragt, Haushofer zu beobachten und über seine Unternehmungen zu berichten. Von ihr erfuhr Haushofer, daß er noch immer in Verdacht war. Seitdem lieferte diese Frau regelmäßig Berichte an die Gestapo, deren Inhalt sie mit Haushof er besprochen hatte. 16

Zweimal wurde diese Frau zu Hitler bestellt und gefragt, was Haushofer über eine Verständigungsmöglichkeit mit England dächte. Wie Hildebrandt ${ }^{17}$ mitteilt, suchte Hitler verzweifelt nach einem Verständigungsfrieden
${ }^{16}$ Ibid., S. 130 .
17 Ibia., s. 132-133. 
mit England und spielte vielleicht mit dem Gedanken, Haushofer als Vermittler zu verwenden. Noch einmal mußte Haushofer mit der Möglichkeit rechnen, von Hitler gezwungen zu werden, ein Amt zu übernehmen. Diese Befürchtung bestätigte sich jedoch nicht.

Der Krieg ging weiter und führte zu einer Wandlung in Haushofers Wesen. Die Wandlung begann im Sommer 1942 mit der Nachricht, sein Lieblingsschüler Wolfgang HoffmannZampis sei gefallen. Darüber schreibt Hildebrandt;

Haushofer hatte das Ende Hoffmanns vorausgefühlt, und doch war es ihm kaum faßbar, daß es so kam. Mir schien, als habe die Nachricht von Hoffmanns Tod Albrecht Haushofer wie aus der Welt gestoßen. Er sprach wenig;, und man spürte, daß in ihm eine große Ruhe eingekehrt war - vielleicht die Ruhe des Menschen, der mit Gewißheit fühlt, daß nun ein letzter Abschnitt seines Lebens begonnen hat. Er wußte, daß es sein Schicksal sein würde, einsam $\mathrm{zu}$ werden. 18

Auf eine ganz andere Weise beschrieb Eva Preiß

Haushofers Stimmung in dieser Zeit.

Bis zu seiner zweiten und letzten Verhaftung war Albrecht Haushofer in derartiger nervlicher Dauerspannung, daß es gelegentlich unmöglich war, mit ihm zu sprechen, denn der geringste Anlaß genügte, den überaus gereizten Mann zum Toben zu bringen. Das Schicksal seiner Freunde und des Vaterlandes schmerzte ihn so sehr, daß er an seiner eigenen Hilflosigkeit seelisch zugrundezugehen glaubte.19

Das Leben wurde für Haushofer ein Abschied - ein Abschied von Werten einer Kultur und ihren beharrenden und bewahrenden Kräften, die in dieser Art nicht mehr:

$$
\begin{aligned}
& { }^{18} \text { Ibid., S. } 174 . \\
& 19 \text { PreiB, S. } 52 .
\end{aligned}
$$


wiederkehren wïrden; ein Abschied von Freunden; Abschied von seiner Wohnung und seinem Institut, die von Brandbomben zerstört wurden.

BewuBten Abschied hab ich oft genommen von allem, was das Leben S.chönes bot: Von Heimat, Werk und Liebe, Wein und Brot. 20

Nach dem Attentatversuch am 20. Juli 1944 wurde Popitz sofort verhaftet, und damit mußte Haushofer mit seiner eigenen Verhaftung rechnen. Er wohnte damals, nachdem sein eigenes Haus ausgebombt worden war, bei Noebbels, einer befreundeten Familie. Bevor er nach Hause kam, telefonierte er stets, um zu erfahren, ob die Gestapo anwesend. sei. An einem der letzten Julitage sagte ihm Frau Noebbel am Telefon, daß "Post" gekommen sei. Das war das Zeichen, daß die Gestapo ihn abholen wollte und für ihn das Signal, sich nicht mehr auf der Straße sehen zu lassen.

Nun begannen die Monate der Flucht vor der Gestapo. Hildebrandt beschreibt die Bewegungen dieser Flucht. 21. Zuerst fuhr er zu seinen Eltern auf der Partnachalm in der Nähe von Garmisch-Partenkirchen. Einige Stunden bevor er dort ankam, wurde sein Vater verhaftet. Nach zwei Tagen bei der Mutter ging er zu FuB zu seinem Bruder zum Hartschimmelhof am Ammersee, ungefähr 50 Kilometer von der Partnachalm entfernt. Hier trafen sich die zwei Brüder für einige Minuten. Durch die hilfsbereiten Schwestern

$$
\begin{aligned}
& 2 \mathrm{O}_{\text {Haushofer, Moabiter Sonette, S. } 33 .} \\
& 21 \text { Ibid., S. } 185 \mathrm{ff} .
\end{aligned}
$$


des nahegelegenen Waldklosters Kerschbach fand er ein Versteck bei einem Bauern. Um die Spur weiter zu verwischen, wurde er von dort zu einem Arzt geleitet. Aber bald entdeckte die Gestapo das Versteck und mit Sekundenvorsprung gelang es Haushofer, in den nahegelegenen Wald zu entfliehen.

Es ist eine alte Erfahrung, daß Menschen, die verfolgt werden, mit ungewöhnlicher Gewalt dorthin gezogen werden, wo sie ihre seelischen Wurzeln haben. Und so wurde der gewöhnlich sehr kluge Haushofer von der lockenden Partnachalm irregeführt. Sein nächtlicher weg führte ihn zu einer seit vielen Jahren mit den Haushofers bekannten Bauersfrau Frau Zahler. Es war Anfang September 1944.

Bis zum 7. Dezember pflegte und versteckte Frau Zahler Haushofer und dann kam der entscheidende Augenblick. Frau Zahler erzählte darüber:

Ich war nicht da, sonst wäre vielleicht alles anders gegangen, und er wäre besser versteckt worden. Es klopfte energisch, und er ist gleich auf die Bühne aufgesprungen und hat in der Aufregung vergessen, die Leiter hinter sich hochzuziehen. Meine Tochter hat aufgemacht. Dann kamen drei Beamte herein und haben alles durchgesucht. Erst am Schluß gingen sie hinauf auf den Boden, und dort fanden sie ihn dann im Heu. Als ich zurïckkam von der Arbeit, wurde er gerade abgeführt. Wie er mich angeschaut hat. Der Mann wußte, daß es jetzt aus war. Und mich hat er noch so dankbar angeschaut. 22

Einige Tage später wurde Haushofer nach Berlin in das Gefängnis an der Lehrter Straße im Stadtteil Moabit gebracht. Der Weg nach Moabit war vollendet. $22_{W}$ Zellner, Münchener Merkur, 27. Mai 1953. 


\section{III: DIE WELTANSCEAUUNG DES DICHCERS}

Albrecht Haushofer war politisch wie persönlich konservativ. Sein reiches Geschichtswissen hat ihn gelehrt, daß Veränderung, Fortschritt und Vorwärtskommen wichtig und nötig sind, man sie aber durch die Kenntnis einer weiterlebenden Tradition und durch nüchterne, weise und unselbstsüchtige Dienste am Staat erreichen muß.

Wenn man das Vertrauen in die Macht des Guten verliert

Wie furchtbar wirkt ein solches Mahnen fort! "Vertraue keinem!" Trägt man dieses Leben, 1 hat solcher Einsicht man sich ganz ergeben?

...wenn Selbstsucht und Gier eines Menschen seine Bereitwilligkeit, anderen zu dienen, überwältigen, wenn man ohne Rücksicht auf die Folgen Tradition leugnet...

Was dieser Wust von Büchern mag ermessen, ist überflüssig, steht es im Koran.

Wo nicht, so schadet's nur. Drum zündet an! ${ }^{2}$

... und wenn ein Mensch um seiner eigenen Macht willen

Wissen miBbraucht...

So wachsen Mord und Brand und Quälerei

mit stolzem Wissen immer neu verbunden, von Menschen ganz allein wird so geschunden. 3

muß die bestehende Ordnung fallen.

Die Noabiter Sonette sowie alle dramatischen werke

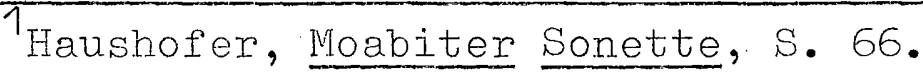

${ }^{2}$ Ibid., S. 53.

3 Ibid., S. 37.
} 
Haushofers sind Zeugnis für den Glauben des Dichters, daß er während einer Zeit lebte, die sich durch moralischen Verfall und Dekadenz mit Eilschritten dern Zusammenbruch nähierte.

\section{Das Erbe}

In Schutt und Staub ist Babylon versunken, ein Tempel blieb vom alten Theben fest, von Ktesiphon zeugt einer Halle Rest, das große Angkor ist im Wald ertrunkenauch unser ganzes Erbe sind Ruinen. Noch kurze Weile zwischen toten Mauern wird kümmerlicher Menschen Sorge dauerndanach wird a.lles nur dem Efeu dienen.

Der Efeu des Vergessens wird sich ranken um ein Jahrtausend hoher Blütezeit, um dreiBig Jahre mörderischen streit. Wir sind die Letzten. Unsere Gedanken sind morgen tote Spreu, vom Wind verjagt, und ohne wert, wo jung der Morgen tagt. 4'

Als politischer Beobachter konnte Haushofer das

Dritte Reich als ein politisches Phänomen betrachten. Er konnte die politischen und ökonomischen Zustände, die Hitlers Aufstieg zur Macht möglich machten, betrachten und verstehen, und er konnte die Methode, die Ziele und die Grenzen des Regimes mit den Augen des objektiven politischen Beobachters: analysieren.

Seine Römertrilogie ist - in Verkleidung römischer Geschichte - ein Angriff auf die illegalen und radikalen Methoden des Nationalsozialismus und eine Warnung vor seinen Methoden und seinen Folgen.

Das erste Drama der Römertrilogie, Scipio, behandelt ein Rom, das in die nüchterne, konservative Regierung 
Scipios und die selbstsüchtigen, nach Macht strebenden Demagogen. gespalten ist. Haushofers eigener Konservatismus spiegelt sich in der Figur Scipios wider. Scipio warnt, aus dem Verständnis des Konservativen für organisches Werden und Wachsen heraus, vor jedem zu schnellen Bruch mit der Vergangenheit, der nur den Kräften gewaltsamen Umsturzes das Tor öffnet. Aber Scipio war durch seinen eigenen Konservatismus zu tief in der Tradition des Rechts als Grundlage des Denkens verwurzelt, um mit Gewalt gegen seine Feinde zu kämpfen. ${ }^{5}$ Obwohl er weiß, daß sein Leben in Gefahr steht, weigert er sich in pessimistischer Resignation, etwas dagegen zu tun. "Ich muß mich stellen, wenn der Blitz mich sucht," 6 sagte er. Das Drama endet mit der Ahnung, daß Scipio sicher ermordet werden wird. Mit seinem Tod wird das Ende der Gültigkeit von Recht und Maß kommen.

Sulla, das zweite Römerdrama, zeigt das römische Reich in den Händen eines Diktators. Die Ähnlichkeiten dieses Dramas zu dem Deutschland unter Hitler sind unverkennbar. Die angeborenen Gefahren eines totalitären Systems, in dem alle politischen Grundsätze und Ziele dem Willen eines einzigen Mannes unterworfen sind, ist das Hauptthema dieses Dramas. Wenn die Macht in den Händen eines Mannes

${ }^{5}$ Felix M. Wassermann. "Macht und Geist in Albrecht Haushofers Römerdramen," Monatshefte für deutschen Unter-richt, deutsche Sprache und Iiteratur.XIVI, Nr. 4 (ApriI7 Nai 1954) S. 214 ff.

$6_{\text {Haushofer, Scipio, S. } 223 .}$ 
liegt, warnte Haushofer in diesem Drama, dann scheitert alles mit seinem Ende:

...scheitert, wenn er stirbt, Weil sein Gesetz in seinem Willen lebt, Und nichts empfängt, was größer ist als er.?

In dem letzten Drama der Trilogie versucht der römische Herrscher, der selbst aus der Machtherrschaft entstand, wieder Recht, Maß und Ordnung in sein Reich zu bringen. Augustus "behandelt den letzten Kampf mit den Kräften persönlichen Geltungsdrangs und Tradition und Disziplin zerbrechender Leidenschaft. Gegenüber dem Kult des Dynamischen mit seiner übersteigerten Ichbetontheit und seinen wilden Träumen, siegt in Augustus der verstandesklare und beherrschte Plan und Wille eines verantwortungsbewuBten und in die Zukunft wie in die Vergangenheit blickenden Staatsmanns." 8

Aber wichtiger als Haushofers Betrachtung des Dritten Reichs als politisches Phänomen und als Aufstieg eines Diktators ist sein pessimistischer Glaube an politische Notwendigkeit oder politisches Schicksal. In dem Schema dieses Glaubens, "Hitler was an agent of a higher force and as such, had a role that would be played to the end despite all human interference... So firmly did he believe in the formative forces of history and in the apparent justice manifested by historical change, that he saw in over-all

\footnotetext{
7 Haushofer, Sulla, S. 185.

8 Wassermann, "Macht und Geist", Monatshefte, XIVI Nr. 4 (April/Mai 1954) S. 219 ff.
} 
historical development a process beyond human direction." 9

Diesen Glauben äuBerte Haushofer selbst in den folgenden Worten, die er über Oswald Spenglers Jahre der Entscheidung sprach:

"Wir sind mitten drin in dieser großen Entscheidung. Wie es niemals um Danzig und den polnischen Korridor ging als der Krieg begann, so geht es auch heute nicht mehr um Herrn Hitler oder einen seiner Potentaten. Es geht auch nicht mehr um Deutschland. Es geht um das Abendland vielleicht sogar die Welt.

Obwohl diese Utberzeugung ihren Schatten in der Römertrilogie vorauswirft, zeigt sie sich am stärksten in Haushofers letzten zwei Dramen, Chinesische Ierende und Die Makedonen.

In Chinesische Iegende wird "das Reich der gelben Erde" von den barbarischen Horden des GroBkhans bedroht. Der Kaiser wird durch seine eigene Iust und seine selbstsüchtigen Träume blind für die Pflichten seines Amts und für die innere und äuBere Not seines Reiches. Er verachtet die Warnungen und den Rat seines weisen und voraussehenden Zensors und das Reich fällt dem Großkhan zu, der, obwohl er ein Barbar ist, die höchste Herrschertugend, die Kraft und Maß vereinigt hält, besitzt.

${ }^{9}$ Charles Hoffmann. Opposition Poetry in Nazi Germany. (Berkeley und Los Angeles University of California Publications in Modern Philology, University of California Press, 1962), S. 61 und S. 64.

$10_{\text {Rolf Italiaander. Besiegeltes Leben. Begegnungen }}$ auf vollendeten Wegen, Gerhart Hauptmann, Ulrich von Hassel und Albrecht Haushofer. (Goslar: Volksbïcherei Verlag, 1949.), S. 44. 
In der Gestalt des Zensors verkörpert der Dichter sein idealistisches Bild eines Staatsmanns, der seine Pflicht gegenüber dem Staat über alles stellt. In diesem Zensor begegnen sich Tradition und Pflicht, Besonnenheit und Recht, als Grundlage des Staates. "Der Zensor vor dem Kaiser im Augenblick der Not vertritt die zeitlose Idee politischer Verantwortung vor dem unwürdigen Träger der Macht."11

Der Kaiser lebt in dem, was war und wird. Die Gegenwart bleibt immer ihm versagt. Wenn er bereit ist, sich im Dienst der Ahnen, Von denen alles kommt, im Dienst der Erben, $\mathrm{Zu}$ denen alles hinführt, $\mathrm{zu}$ vollenden, Dann mag das Glück an seinem Herzen wachsen, Das größte Last als größten Trost erkennt. 12

Die Makedonen drücken des Dichters Überzeugung aus, daß Geschichte von einer höheren Kraft bestimmt werde, und seinen Glauben, daß die Kraft der Geschichte eine Änderung verlangt, wenn eine Epoche ihre Lebenskraft und Lebensfähigkeit verloren hat.

Das Thema dieses Dramas behandelt das Reich der Makedonen kurz vor dem Zusammenbruch, der durch den Tod Alexanders bewirkt wird. Wie in Sulla hält ein Mann den ganzen Staat in seinen Händen. Obwohl Alexander selbst nie auf die Bühne tritt, "lebt er in allem, im Guten

11 Felix M. Wassermann. "Albrecht Haushofers Chinesische Legende, Monatshefte für deutschen Unterricht, deutsche Sprache und Literatur, Vol. 42 . No.

${ }^{12}$ Albrecht Haushofer, Chinesische Legende: Eine aramatische Dichtung. (Berlin: Lothar Blanvalet Verlag, 1949, S. 38 . 
und im Schlechten. Er ist der unsichtbare Pol, um den die Leidenschaft und die Geister, die Völker und ihr Schicksal kreisen. Dieser Pol - in Gestalt eines Menschen - ist die Kraft, die alle Gegensätze zusammenhalten und in sich vereinigen kann."13

Perdikkas, der kluge Kanzler Alexanders, und Nearchos, der Admiral, erkennen die Gefahren, die der Tod Alexanders mit sich bringen könnte. Deshalb versuchen sie anfangs zu verschweigen, daß Alexander krank ist. In den Worten Perdikkas:

Der König darf

Im Aug' der Welt nicht krank sein. Dieses Reich

Lebt aus dem blinden Glauben aller Menschen An seine GröBe. Schon allein das Wissen, Daß Alexander krank sei, daß er nicht In jeder Stunde dort erscheinen könnte, Wo sein Befehl erwartet wird, gefährdet Die Ordnung unserer Welt. 14 .

Eine genaue Erklärung der Krankheit Alexanders gibt uns der Dichter nicht, und der Leser ahnt, daß die Krankheit einen unnatürlichen und unerklärbaren Ursprung hat. "Die Geschichtsschreibung läßt Alexander an den Folgen einer Infektion sterben. Haushofen nimmt diesem Tode alles Zufällige. Alexander stirbt, weil sein Leben zu Ende geströmt ist, ex hat sich innerlich verzehrt. Die Krankheit ist nur eine Vollstreckerin

13 Hildebrand, S. 116.

${ }^{14}$ Albrecht Haushofer, Die Makedonen, (Unveröffentlichtes Manuskript) Acte III, Scene II. 
des inneren Todesurteils."15 In dieser menschlichen Krankheit symbolisiert Haushofer die Krankheit einer Epoche.

Nearchos:

...Die Krankheit ist

Ein Kampf in seiner Seele, ein Ermatten

In seinem tiefsten Herzen, nicht allein

In seinem Körper. Wenn er leben sollte,

Und stirbt er - nein,

Ich kann's nicht, darf's nicht denken--

Aristoteles:

Dann stirbt er, weil er schicksalsmüde war,
Der Brandungswelle gleich, die sich gebrochen.

Als Alexanders schwere Krankheit nicht mehr verborgen werden kann, versuchen Perdikkas, Nearchos und Alexanders Generäle, die Frage eines Nachfolgers zu entscheiden und Pläne für die Zukunft zu schmieden.

In diesem reifsten aller Dramen Haushofers gelang es ihm, eine Spannung zu schaffen, in der der Leser ständig, trotz der Versuche der Stellvertreter Alexanders, das Reich zusammenzuhalten, das unvermeidliche Verhängnis des Makedonischen Reiches spürt.

Als die Gerüchte von Alexanders bevorstehendem Tod die Stadt durchlaufen, fängt bereits die Meuterei an. Nach seinem Tod, während eine machthungrige Partei nach der anderen die Bühne durchkreuzt, zündet Alexanders Mutter den Palast an. Durch dieses dramatische Feuer, ein Symbol der zerstörenden Kraft eines Naturelements, symbolisiert Haushofer den Fall eines Reiches,

15 Hildebrandt, S. $117 \mathrm{~F}$.

16 Haushofer, Die Mgkedonen, Acte IV, Scene I. 
einer Epoche.

Es ist wichtig und bedeutsam zu wissen, daß Haushofer dieses Drama während seiner ersten Gefangenschaft schrieb. Zu dieser Zeit fing der RuBland-Feldzug an. Für. einen Mann wie Haushofer, der die Fähigkeit besaß, eine Situation so rationell und klar zu analysieren, mußte: diese Handlung Hitlers völlig verantwortungslos erscheinen.

Wie in Die Makedonen so spricht auch aus den Sonetten die Ứberzeugung, daß es nur eines Agenten bedarf, um bewußt oder unbewußt die Waage, die die WeIt in unsicherer Balance hält, zu kippen, wenn die Zeit für historische Änderung reif ist.

Lawinen

Wem je die hohen Berge. Heimat waren, der weiß, wie man die Hänge meiden muß, an denen, in zermalmend-jähem Schuß, Lawinen donnernd in die Tiefe fahren. Da mag ein ganzer Berg in Stille lauern, der kleinste Schneeball reißt die Hüllen auf, und weiBe Lasten tosen ihren Lauf. Begraben Täler unter Todesmauern.

Vermessenheit, Iawinen loszulösen!

Verbrecher, wer sich des Zerstörens freut. Und Narr zugleich, wer nicht den Wurf bereut!

Vermessenheit im Guten oder Bösenich büBe den Versuch, sie aufzuhalten. Ein StoB - ein Wirbel - tödliches Erkalten...17

Ein anderer Aspekt von Haushofers konservativer Weltanschauung, der in den Moabiter Sonetten hervortritt, ist sein Glaube an den Wert der Tradition, an das Erbe.

17 Haushofer, Noabiter Sonette, S. 22. 
eines Volkes. "Tradition, nicht als Fremder oder als bloße Form, sondern als angemessener Ausdruck des. eigenen Wesens, weil man aus demselben Stoff ist, aus dem die Vorfahren waren..., Tradition der Familie, des heimlichen Stammes, des eigenen Volkes, der Menschheit."18 In der Tradition sah er und suchte er das ewig Gieiche: im Boden und in der menschlichen Natur, das in Jahrtausenden ewig gleiche Formen der Ordnung und des Kampfes hervorgebracht hat. Diese Suche nach den ewig gültigen Werten ist in all seinen Dichtungen zu sehen. Haushofer glaubte, daß der Gegenwart Maß (ein wichtiges Wort für Haushofer) fehlt, wenn man die Vergangenheit mit ihren Traditionen und Iehren verleugnet. Dieses Maß ist auf der Basis der Vergangenheit gegründet. Dem Dritten Reich fehlt durch seine Verleugnung und seinen MiBbrauch der Vergangenheit dieses Maß. Durch diesen Begriff des Maßes wollte der Dichter sagen, "that there is no 'moderation' in the Nazi tactics, but he also means and this is more important - that the Third Reich allows no standard of value against which Hitlers administration may be "measured." When the state lacks such an external measure, then one can no longer speak of its program, its ideology or its Weltanschauung for these things do not exist, except on paper."19

\footnotetext{
18 Weizsäcker, "A. Haushofer und die Jugend",S. 18. ${ }^{19}$ Hoffmann, Opposition Poetry, S. 62.
} 
Begreift Ihr, was Ihr tut mit Euren Spielen, atomzertrümmernde Raketenzünder, totaler Kriege schäumende Verkünder!

Was bleibt am Schluß von allen Euren Zielen? Ist alles Überlieferte zerstört, fehlt Euch sogar ein Erbe, der Euch hört! 20

Diese völlige Vernachlässigung der Zukunft, dieses Leben nur für den Augenblick, ist das Thema des Gedichts, "Persische Legende." Der Leser muß vorsichtig sein, um von dem äuBeren humoristischen Ton des Gedichts nicht irregeleitet zu werden.

\section{Persische Legende}

Im alten Schiras ließ ein Schelm verbreiten, er lehre seinen Esel, wie man spricht. Der Schah erfuhr's, befahl dem frechen Wicht, den klugen Esel zum Palast zu reiten. "Du lehrst ihn sprechen?" "Ja!" "Was forderst du für deine Kunst?"Fünf Jahre Zeit und Iohn." "Gewährt. Doch spricht das Tier dann nicht, mein Sohn, gibt's hundert Peitschen für das Jahr dazu!" Der Schelm, der Esel bleiben in der Pracht. Ein Freund besucht die beiden im Palast und fragt besorgt: "Was du versprochen hastbegreifst du, was es heißt?" - Der andre lacht: "Der Schah-der Esel-ich-was ist dabei? Wir können täglich sterben - alle drei!"21

Daß Menschen vergessen haben, daß Geduld und Zeit nötig sind, um ihre Probleme zu lösen, ist das Thema des Gedichts "Der Fasan." Der Dichter erzählt die orientalische Parabel von einem Künstler, dem es erst nach vier Jahren und nach hunderten von Versuchen gelang, ein voliendetes Bild eines sterbenden Fasans zu malen. Die

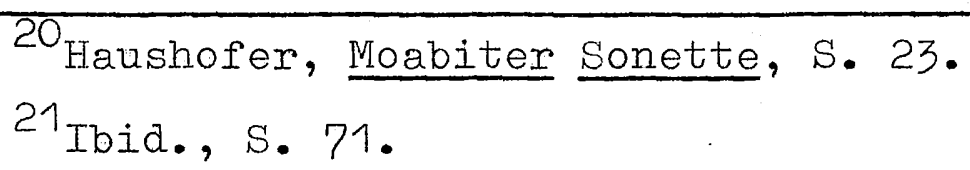


letzten arei Zeilen lauten:

So lehrt ein Künstler Schöpfertum der Tage.

Von Gottes Welt - so geht nun das Geschrei wird gleich gefordert, daß sie fertig sei. $2 \overline{2}$

In dem Licht seines pessimistischen Glaubens und seiner Resignation sollen die folgenden Verse verstanden werden:

Dann weiß ich, aus den Träumen aufgestört, wie einer fühlt in seinen letzten Stunden, der an ein ruderloses Boot gebunden, den Fall des Niagara tosen hört. Die Wasser schlagen an des Bootes Rand. Sie strömen rasch. Gebunden - ist die Hand...23

In diesen Versen benützte der Dichter das Wasser als symbol der unkontrollierbaren Kraft, die alles, was in ihrem Weg steht, mit sich fortreißt. Das Symbol findet man in anderen Sonetten. In "Die Große Flut" zum Beispiel:

Den Mississippi hab ich einst befahren, als unter seiner Fluten brauner wucht an tausend Meilen bis zur großen Bucht ringsum die Fluren tief begraben waren. Ein öder Spiegel, wo zuvor Gedeihen von grünen Saaten, goldnen Ernten war, wo vieler Hände Fleiß von Jahr zu Jahr daran geschaffen, Heim und Héim zu reihen. Was flüchten konnte, floh, das andre ${ }_{\text {starb. }}$
Die weite Fläche war an Leben leer.

In diesen Gedichten, sowie in "Lawinen" herrscht Haushofers Pessimismus vor, daß alle Versuche, die flut aufzuhalten, hoffnungslos sind. Man muß sich fragen, ob

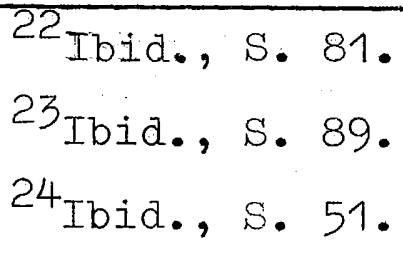


er keine Hoffnungen für die kommenden Generationen sah. Hier lautet die Antwort positiv.

Sein Glaube an politischen Notwendigkeit, der zuerst völlig pessimistisch scheinen mag, führt zu dem schluß, daß "Historical justice forces an end to every epoch once it is no longer vital... it does this so that a new era may begin... Haushofer's faith in a creative principle inherent in history is coupled with a conviction that the course of earthly events must ultimately be directed towards the good of man."25

Die Großen Toten

Wenn sich das deutsche Schicksal ganz erfüllt: Die Herren ohne Maß nur Knechte sind und bleiben bis auf Kind und Kindeskind, wenn alles winseln wird, was heute brüllt, wenn alles kriechen wird in Schmutz und Pein, und nichts mehr zeugt von echter Leidenschaft, dann werden mit gewaltig strenger Kraft die großen Toten ihre Sprecher sein. Ein Kant, ein Bach, ein Goethe werden Zeugen noch lange für zerstörtes VoJk und Iand, auch wenn die Menge nie den Sinn verstand. Nie brauchen große Tote sich zu beugen vor Aberwitz und Schmach. Ihr Geist besteht, solang der Atem Gottes aus ihm weht.26

Denselben Glauben an die Zukunft sieht man in den beiden Sonetten, die das berüchtigte Bücherverbrennen der Nazis zum Thema haben. In "Verbrannte Bücher" wendet er sich wieder an die Geschichte des Morgenlandes, um einen chinesischen Despoten mit Hitler zu vergleichen. Der Despot versuchte durch Verbrennen der Bücher, das Wis-

$$
\begin{aligned}
& 25_{\text {Hoffmann, Opposition Poetry, }} \text { S. } 71 . \\
& 26_{\text {Haushofer, Moabiter Sonette, }} \text { S. } 56 .
\end{aligned}
$$


sen und die Weisheit der Vergangenheit zu zerstören.

In den Quartetten beschreibt der Dichter den Mord und den Brand der Schreckensherrschaft. In dem Sextett entsteht jedoch wieder alles, was der Zwingherr zu vernichten, versucht hatte.

Im zwölften war der große Zwingherr tot. Die alten Bücher wurden neu geschrieben, von denen, die am Leben doch geblieben...

Der nächste Kaiser, der im Land gebot, war allem Denken freundich zugewandt: Hat Bücher nicht, hat Weise nicht verbrannt. 27

Noch ein Beispiel dieses Glaubens und dieser Hoffnung findet man in den folgenden Versen, in denen der Dichter die Idee der Natur und des Naturgesetzes benutzt, um seinen Glauben an die Auferstehung des Guten zu äußern.

Doch ahnt ein Winter schon den Frühlingswind. Es kommt der Tag, wo die Motoren schweigen und Frieden läuten wird ein Glockenreigen.28

Sein Glauben an eine Weltordnung, auf Maß und Harmonie gegründet, ist das Thema des Sonetts "Kosmos." Dieses Gedicht enthält eine starke Bestätigung des Glaubens an eine Weltordnung, die jenseits des Bereichs menschlicher Handlung und Herrschaft ist.

Kosmos

$\mathrm{Ob}$ sich in Klängen wie zu freier Wahl, im Keplerschen Gesetz ihr Sinn enthüllt, es muß wohl sein, daß diese Welt erfüllt geheimnisvolle Harmonie der Zahl.

In Strahl und Schwingung zu gemessnem Spiel umwebt sich aller stoff und löst sich wieder, und alle Formen sind gewollte Glieder

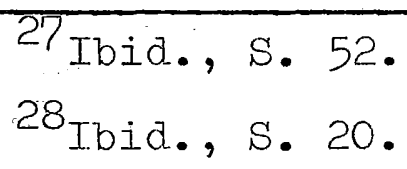


in einem Weltgesetz, vor einem Ziel.-

Wer je den großen. Bau der Welt bedacht und fühlte nicht, wie Gottes hoher Geist noch über den Gesetzen wacht und kreist-

Wie blind erscheint, wer Schöpfertum verlacht! Wir kennen kaum den kleinisten Teil davon:

Gesetz ist Wunder, Zahl ist Weltenton. $29^{\text {. }}$

ObwohI die Moabiter Sonette Haushofers Optimismus und seinen Glauben, daß Ordnung und Recht wieder entstehen würden, bestätigen, sind sie überwiegend pessimistisch, im Ton. Dieser anscheinende Widerspruch erklärt sich, wenn man an die Bedeutung, die die Sonette für Haushofer persönlich enthielten, denkt.

In den Sonetten äußerte Haushofer seine Überzeugung, daß die Epoche, zu der er gehört, an ihrem Ende angelangt war. Er glaubte, daß sein eigenes Ende mit dem Ende der Epoche kommen müßte;

Wenn man in so viel Vergangenheit zu Hause ist und ich bin es durch Familie, durch Wissen und durch sehr empfindliche Antennen - dann hat man ein sehr festgewordenes Bild davon, wie lange man noch Zeitgenosse einer neuen Zeit sein darf. Ich gehöre...noch zur einer Art des Denkens und Zusammenhaltens, die ein Ende nimmt. Was heute mit Bomben und im Innern der Menschen zerstört wird, ist dazu nur ein äußeres, was im Grunde schon geschehen ist. Wenn alles auseinandergeht und man das Ganze und nur das Ganze sieht, dann kommt die Stunde, da man weichen kann. Wie das neue Haus dann einmal aussehen wird, weiß ich nicht, Nur: daß ich nicht hineingehöre. Mein Schicksal ist es, das Vergehende mit letzter Bewußtheit noch zu halten. 30

Diese Utberzeugung, die er in dem obigen Prosazitat ausarückte, äußerte er auch in folgenden Versen

${ }^{29}$ Ibid., s. 79.

$30_{\text {Hildebrandt, }}$ s. 27. 
aus den Moabiter Sonetten:

Wir sind die Letzten. Unsere Glauben sind morgen tote Spreu, vom Wind verjagt, und ohne Wert, wo jung der Morgen tagt.31 
IV. DIE MOABITER SONETTE

THEMEN UND MOTIVE:

Der Bereich der Themen der Moabiter Sonette ist breit und mannigfaltig. Die Fäden, die sie zu einer Sammlung zusammenbinden, sind die Tatsachen, daß sie alle während der Gefangenschaft des Dichters geschrieben wurden und daß fast alle sich irgendeines persönlichen Erlebnisses aus dem Leben des Dichters erinnern. Wie Charles Hoffmann ${ }^{1}$ in seiner Darstellung von Albrecht Haushofer als einem Widerstandsdichter schreibt; "to evaluate the collection correctly, one must see in it a sort of monologue in verse, a poetic diary whose entries recall a variety of personal experiences, memories and ideas."

Der Dichter hält in einer großen Mehrzahl der Moabiter Sonette eine Art innerer Zwiesprache mit sich selbst. Sie sind ein dichterisches Zeugnis dafür, daß der Dichter durch die Erinnerung an seine vergangenen Erfahrungen und Erlebnisse una durch Nachdenken über die Schwere der Gegenwart eine Wandlung erfuhr, in der er neue Bedeutung für sein Leben und neue Kraft fand, diese schweren Monate zu überstehen.

In der Selbstprüfung und der schließlichen Selbstüberwindung des Dichters erreichen die Moabiter Sonette: ihre Vollkommenheit.

Toffmann, Opposition Poetry, s. 58. 
the man manche der Sonette richtig verstehen kann, ist es notwendig, etwas von den zugrundeliegenden Ereignissen zu wissen. So meint Eva Preiß: "Daß sich aus dieser gedankenschweren, bilderreichen Dichtung sehr leicht eine Fehlinterpretation ergeben kann, liegt auf der Hand, weshalb es immer wieder notwendig ist, das Ieben und die geistige Grundhaltung als Wertmaßstab zu benützen." 2

Mit diesem Maßstab als Führer brauchen die meisten Sonette keine umfassende, weitere Interpretation. Die Sprache, die der Dichter verwendet, um seine Gedanken und Ideen zu äußern, ist in den meisten Fällen klar, und der Leser wird nicht daran gehindert, den Begriff und die Bedeutung, die der Dichter ausarücken wollte, zu verstehen. Die Sonette, die in den folgenden Seiten dargestellt werden, teilen sich in drei allgemeine Kategorien: 1) die einer autobiographischen Natur, wo der Dichter sich seiner Familie, seiner Heimat, seiner Freundschaften und seiner umfassenden Reiseerfahrungen erinnert und 2) die, in denen er seine Verzweiflung über die Sinnlosigkeit und Grausamkeit des Krieges äußert; jene, die durch seine Einfühlung und seine Nähe zu seinen Mitmenschen motiviert werden; und solche, in denen die Sehnsucht des Dichters nach Freiheit ihren Ausoruck findet. Und schließlich 3) die Gedichte, die die innere Wandlung und Selbstüberwindung ausdrücken.

$$
{ }^{2} \text { Preiß, s. } 119 \text {. }
$$




\section{Die Mutter}

In einem der schönsten und zärtlichsten sonette schildert Albrecht Haushofer den letzten Abschied von seiner Mutter. Es war ihm klar, daß er auf der Partnachalm bei der Mutter nicht verweilen konnte. Hildebrandt ${ }^{3}$ berichtet, daß Mutter und Sohn nur zwei Tage lang beisammen waren. Diese letzten Stunden mit der Mutter waren nur ein großes Schweigen, - bei angehender Nacht mußte er fortgehen. Wohin er gehen sollte und was sein Schicksal sein würde, waren Fragen ohne Antwort. Als er den Weg über die Wiesen ging, auf denen er als Junge Heu getragen hatte, schaute er wiederholt zu seiner Mutter hinauf, die in der Türe stand und ihm nachschaute.

Mutter

Ich sehe Dich in einer Kerze Iicht im Rahmen einer dunklen Pforte stehn. Du spürst die Kühle von den Bergen wehn. Du frierst ja, Mutter...dennoch weichst Du nicht.

Du schaust mir nach, der in die Nacht enteilt. in dunklen Schicksals ungewisse Frist, mit einem Lächeln, das nur Weinen ist, mit einem Schmerz, den kein Vertrauen heilt. Ich sehe Dich in Deiner Iiebe Iicht, im Zittern Deiner weißen Haare stehn. Du spürst die große, dunkle Kühle wehnund langsam, langsam senkt sich Dein Gesicht. Noch immer leuchtet fern der Kerze Schein- 4 Du frierst ja, Mutter... Mutter-geh hinein...4

Nartha Haushofer stammte aus einer jüdischen Familie, deren S.tammbaum eine ganze Kette von Gelehrten und Kauf-

\footnotetext{
3 Hildebrandt, S. 187

${ }^{4}$ Haushofer, Moabiter Sonette, S. 40.
} 
leuten aufweist. Als junges Mädchen war sie - wie ihr Sohn auch - still und verschlossen, suchte wenig Kontakt $\mathrm{zu}$ anderen. 5

Haushofer fühlte sich geborgen in der Ruhe der Mutter, der er im Innersten so ähnlich war: in der Klarheit und Bewußtheit des Erlebens, in der Schwere des Tragenmüssens und Dankbarkeit des Tragendürfens. 6

Die Mutter Haushofers hatte zusammen mit einer zarten Weiblichkeit einen scharfen, logischen Verstand, wie er eigentlich nur in dem Gehirn eines Mannes waltet. Sie sprach leise, ein wenig wehmütig und doch entschlossen, in kurzen Sätzen, mit einer sehr hohen Stimme. Aber wenn sie von sozialen Fragen oder vor einem Verein für Fraueninteressen sprach, kam Feuer in ihre Worte. Mit derselben Glut spielte sie ihre mütterliche Rolle.?

In diesen letzten Stunden, bevor er fliehen mußte, konnte Haushofer seine Mutter nicht mit Beruhigungen täuschen. Die Unsicherheit der Zukunft, die sowohl Wutter als auch Sohn spürten, spiegelt sich in diesem Sonett wider. "Die große, dunkle Kühle", die die Mutter wehen spürte, wurde zum Symbol für die unbekannte Zukunft.

\footnotetext{
${ }^{5}$ Hildebrandt, S. 42.

6rid., S. $126 \mathrm{f}$.

7 Hermann Heimpel, Die halbe Violine. Eine Jugend
} in der Residenzstadt Miunchen. (Stuttgart: K.F. Koehler Veriag, 1949), S. 270. 
Diese Frau, die sich selbst nie außer Gefahr des Judenhasses des Nationalsozialismus fühlte, bewahrte immer ein warmes, mütterliches Ferz für die Ieiden anderer Menschen. 8 Dieses äuBerte Faushofer, als er schrieb, "...Du schaust mir nach, der in die Nacht enteilt,/ in dunklen Schichksals ungewisse Frist,/ mit einem J.ëcheln, das nur Weinen ist,/ mit einem Schmerz, den kein Vertrauen hejlt."

Aus ihrer großen Liebe schöpfte Haushofer Mut und Kraft, seinen ungewissen Weg fortzusetzen. Von dem ersten Bild der Mutter, wo sie im Licht einer Kerze steht, steigt die Schilderung bis zum Höhepunkt in Zeile neun, "Ich sehe Dich in Deiner Iiebe Iicht;" hier vergleicht Haushofer die Liebe seiner Mutter mit dem Licht eines Heiligenscheines.

Aller Schmerz, den man bei solchem Abschied fühlt, spiegelt sich in diesem Sonett wider. Durch das Benutzen einfacher Wörter und das al.Imähliche Verlangsamen des Rhythmus erreicht der Dichter einen Höhepunkt im letzten Vers des Sonetts. Der Leser fühlt den tiefen Schmerz, und der Vers weist auf die innere Anstrengung hin, sich zu beherrschen.

Ein anderes Sonett, in dem die Viutter die Hauptfigur darstellt, ist "Schwanenring." Es hat die Form eines Testaments. Den Siegelring, den ihm seine Mutter geschenkt hatte, hinterließ er ihr. Der Ring ist Symbol

\footnotetext{
PreiB, S. 19.
} 
der Familientradition und der Dichter hofft, daß diese Tradition durch die Kinder seines Bruders fortgesetzt wirde.

\section{Der Schwanenring}

Den Siegelring aus Deinem Ahnenkreis, ich ließ ihn, Mutter, Dir. In Deiner Fut bin ich gewiß, daß er in Treue ruht, der viel von meines Lebens Bahnen weiß. Das Wappen, das er führt, den weißen Schwan, der mächtig schlagend seine schwingen hebt und zwischen Sternen in den Himmel strebtein Kaiser gab ihn ejnem fernen Ahn.

Fr siegle weiter. Komm ich nicht zurïck, so steck ihn - gehst Du selbst ins andre Land dem tüchtigsten der Neffen an die Hand und sag ihm: Schwanenflug bedeute Glück... Gedenkt er dessen, der sein Frbe trug 9 nur einen Tag im Jahr, so sei's genug.

Dieses Sonett ist eines der am wenigsten erfolgreichen. Dem Dichter ist es nicht gelungen, seine Gedanken in einer klaren und konsequenten weise darzustellen. Man ahnt hier, daß er durch die Sonettform zu sehr beschränkt wurde. Die Anforderungen der Form verhindern das Fließen des Gedankens. 


\section{Der Vater}

Die zwei Sonette, die sich mit der Auseinandersetzung mit dem Vater befassen, sind besonders wichtig. Karl Haushofer, der so viel wußte und voraussah, wurde, wie so mancher Mensch, im Augenblick der Entscheidung blind. Niemand hat besser als der Sohn die Tragik des Geopolitikers gesehen.

\section{Der Vater}

Ein tiefes Märchen aus dem Morgenland erzählt uns, daß die Geister böser Macht gefangen setzen in des Meeres Nacht, versiegelt von besorgter Gotteshand, bis einmal im Jahrtausend wohl das Glück dem einen Fischer die Entscheidung gönne, der die Gefesselten entsiegeln könne, wirft er den Fund nicht gleich ins Meer zurück. Für meinen Vater war das Ios gesprochen. Es lag einmal in seines Willens Kraft, den Dëmon heimzustoßen in die Haft.

Mein Vater hat das Siegel aufgebrochen. Den Hauch des Bösen hat er nicht gesehn. Den Dämon ließ er in die Welt entwehn.10

Dieses Sonett, in dem Haushofer wohl die Geschichte "Der Fischer und die Djenie" von den Arabischen Nächten verwendet, um den Vergleich zwischen der alten Legende und seinem Vater zu machen, zeigt keine Verdammung oder Bitterkeit über die Tatsache, daß sein Vater eine wichtige Rolle beim Aufstieg des Nationalsozialismus spielte. Vielmehr drückte er diese unleugbare Tatsache schlicht und klar aus.

$$
10 \text { Haushofer, Moabiter Sonette, S. } 47 .
$$


In Beziehung zu seiner "politischen, Notwendigkeit Philosophie", bedeutet ihm der Dämon der Flasche die vernichtende Gewalt des Bösen. Obwohl dieser böse Geist gewöhnlich "von besorgter Gotteshand" kontrolliert wird, vermag ein Mensch - in diesem Fall sein Vater - manchmal, den Dämon freizulassen. Die Verse 5 bis 9 deuten an, daß solche Momente, in welchen ein Mensch zwischen Gutem und Bösem zu wählen gezwungen wird, von Glück und $\mathrm{Zu-}$ fall bestimmt werden. ("Für meinen Vater war das Los gesprochen.") Wenn jedoch das Siegel aufgebrochen ist und der Dämon freigelassen, muß der Mensch selbst die Verantwortung dafür übernehmen und die Folgen tragen. 11

Karl Haushofer kam erst durch seine äußerst enge Freundschaft mit Rudolf Heß in Beziehung zu dem Nationalsozialismus. Nach dem Münchner Putsch kam Heß zu seinem Freund, um sich bei ihm vor der Polizei zu verstecken. Später, als Hitler und Heß im Gefängnis saßen, brachte Karl Haushofer ihnen Bücher, die Hitler haben wollte. "Daß für Hitler jedes Wissen allerdings nur Mittel zum Zweck seines Machtgewiones sein konnte, das wußte der Vater ebensowenig, wie daß Hitler mit Hilfe dieser Bücher... Mein Kampf schrieb. 12

Nach einer erfolgreichen Militärkarriere, während der er zwei eindrucksvolle Jahre in Japan verbracht hatte, wandte sich Karl Haushofer einem akademischen, wissen-

\footnotetext{
${ }^{11}$ Hoffmann, Opposition Poetry, s. 67.

12 Hildebrandt, S. 35.
} 
schaftlichen Leben zu. Doch wegen eines Iungenleidens verbrachte er nach seiner Rückkehr von Japan zwei Jahre in der Schweiz. In diesen Jahren reiften in Karl Haushofer die japanischen Eindrücke zu einem Werk, aus dem sein großes Verständnis für die Nöte des unverbrauchten, jungen, aufstrebenden Inselvolkes sprach, das ihm wie eine deutsche Schwesternation erschien. Im Jahre 1912 promovierte der 43jährige Haushofer an der Universität München zum Doktor der Philosophie.

Im Jahre 1919, nach dem ersten Weltkrieg, wurde er Privatdozent für Politische Geographie und zwei Jahre später Fonorarprofessor in München.

Der junge Albrecht fand in seinem Vater ein Vorbild. Seine politischen und wissenschaftlichen Neigungen erbte er ohne Zweifel von dem Vater. Aber er erbte auch seines Vaters große Iiebe zur Iiteratur. In zwei Generationen vereinigten sich Gelehrter und Künstler in jeweils einer Ferson. Diese Tradition setzte sich in dem. Sohn Albrecht fort.

Hermann Feimpel schrieb in Die halbe Violine über den Vater: "Leise, doch in singenden Bögen der Phantasie sprach Vater Haushofer und nahm die Buben - so nannte er die Akademiker - ernst, a.ls wären sie Männer, Gefährten seiner Fahrten und Phantasien."13 Die lebendige Art des Vaters, von Menschen und Erlebnissen zu erzählen, die 
Schilderungen seiner Reisen, die Persönlichkeiten von Rang und Namen, die in das Elternhaus kamen, übten einen starken EinfluB auf den jungen, empfindsamen Albrecht $\operatorname{aus.~}^{14}$

Die Romantik war ein bestimmendes Element in dem Haushofer-Haus. Es herrschte ein feingeistiger Ton. "Die Familie war eine Einheit in Urteil, Gefühl, Wort und Ton," schrieb Hermann Heimpel. "Wie der Vater schien der Sohn in anderen Zeiträumen zu denken, nach einem anderen Ziel zu leben als wir Europäer, von der Weisheit des chinesischen Zensors war viel die Rede und von einem freien, selbstgewählten, gelassenen Tod."15

Wenn man an eine Familienatmosphäre denkt, in der intellektuelle und geistige Interessen die Familie so eng verbinden, ist es leicht uu verstehen, welcher Zwiespalt durch die politischen Auseinandersetzungen zwischen Vater und Sohn entstehen mußten. Albrecht Haushofers Bruder, Diplom-Landwirt Dr. Heinz Haushofer, schrieb, daß sein Bruder und sein Vater, "die letzten Jahrzehnte wie die beiden Hälften eines Stereoskops" erlebt hätten. ${ }^{16}$

Diesen Unterschied, der den Sohn von seinem Vater trennte, schildert Haushofer in dem Sonett, "Acheron." Ein groBer Dichter hat das Wort geprägt, man müsse selbst den Acheron bewegen, wenn sich zur Hilfe nicht die Götter regen.

${ }^{14}$ Hildebrandt, s. $43 \mathrm{f}$.

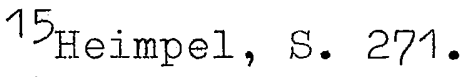

16 Hildebrandt, s. 31 . 
Mein Vater hat es oft im Trotz gesagt.

Mein Vater war noch blind vom Traum der Macht. Ich hab die ganze Not vorausempfunden. Zerstörung, Brand und Hunger, Tod und Wunden,

Hier gibt Haushofer zu, daß sein Vater wissentlich die nationalsozialistische Idee unterstützte und von einem Machttraum irregeführt wurde. Nach diesem Zugeständnis in Vers 5 ändert sich die Stimmung des Gedichtes. Die Verse 6 bis 8 zeigen Haushofers Verzweiflung - es ist, als ob er seinen Vater fragen wollte, warum er nicht - wie sein Sohn - das kommende Verhängnis voraussähe. Diese Verzweiflung steigt weiter in dem Sextett, bis zum letzten Vers, wo der Leser leicht verstehen kann, was diese tragische Auseinandersetzung, die Vater von Sohn trennte, für Haushofer selbst bedeuten mußte.

BewuBten Abschied hab ich oft genommen von allem, was das Ieben Schönes bot: Von Heimat, Werk und Liebe, Wein und Brot. Nun ist das Dunkel über mich gekommen. Der Acheron ist nah, das Leben fern. Ein müdes Auge sucht nach einem Stern.

In diesem Zusammenhang ist es interessant zu zitieren, was Haushofer früher über seinen Vater und sein Verhältnis zum Nationalsozialismus gesagt hat:

Es stimmt, daß der Vater mit seinen Schriften bewußt $z u$ einer deutschen Großmachtreife beitragen wollte. Es stimmt, daß der Gebrauch - aber noch mehr der MiBbrauch - seiner Theorien dem Nationalsozialismus zugute kam. Dennoch ist der Vater alles andere als ein Nazi. Das alles versteht man vielleicht, wenn man zwei Dinge weiß: das eine ist, 
46

wie das Weltkriegsende auf einen vaterlandsliebenden Mann vom Schlage meines Vaters wirken mußte: Daß man Deutschland zahlen ließ und es seiner politischen und militërischen Macht enteignete, konnte er verstehen, äber daß man deutsche Gebiete amputierte, das hat er innerlich nicht ertragen... Nun kommt als zweites hinzu, daß der Vater bis 1938 den Nationalsozialismus völlig falsch sehen mußte, weil er nur durch die schönfärbende Brille seiner Freundschaft $z u$ HeB in sein Blickfeld kam. 18

Und es stimmt, daß kein Haushofer, der Vater eingeschlossen, Mitglied der Nationalsozialistischen Partei war.

Die Auseinandersetzung zwischen Vater und Sohn dauerte bis zum Ende. Durch den Selbstmord des Elternpaares zur Zeit des Nürnberger Prozesses am 10. März 1946, gibt Karl Haushofer seine Fehler zu. "Quelques mois plus tard, Karl Haushofer, obsédé par la mort de justifier sa vie, se suicidait, réalisant ce "junshi", cette mort d'accompagnement, que sa science du monde japonais lui avait rendue familière."19

\footnotetext{
18 Hildebrandt., S. 33.

19 Michael Hobart, "Ies nouveaus masques de la mort et la lyrisme allemand contemporain: Albrecht Haushofer's 'Moabiter Sonette' et Rudolf Hagelstange's 'Ballade vom verschütteten Leben'," Critique: Revue générale des Publications francaises et etrangeres, (Tome IX, $\overline{\text { No }} 77$ (October, 1953), S. 841.
} 


\section{Heimat}

Albrecht Haushofer schrieb einige Sonette, die seine Liebe zu den Bergen seiner bayerischen Heimat widerspiegeln. Man spürt darin seine enge Verbundenheit mit der Natur. Während einer Zeit, in der Zerstörung und Vergänglichkeit herrschten, kommen dem Dichter seine Heimat, die Berge und die Natur wie ein Symbol der Unvergänglichkeit und des Unzerstörbaren vor. Wenn er von seiner über alles geliebten Heimat spricht, und über "ihrer Berge Mauern im Hintergrund", verbindet sich irgendwie mit dem Bild der Bergmauer die Vorstellung von Ruhe und Geborgenheit.

Partnachalm

Von allen quaderfest gefügten Mauern in Hof und Haus, in städtischem Besitz, wird wenig bleiben in der Zeiten Blitzder kleine Bau von Holz allein mag dauern. Sein Dach ist fern von allen Kampfeszielen, im Winter tief in weiBem Schnee versteckt, im Sommer hoch von grünem wuchs gedeckt, von grünem Wuchs, darin die Winde spielen. So darf es noch vielleicht in späten Jahren, dem Tal entrückt und nur dem Berg vertraut, an dessen Flanke sich das Wetter staut, den Erben seinen Zauber ganz bewahren. Wer Frieden, Rast, Versenkung suchen willdort findet er's...Wie sind die Nächte still! 20

Wahrscheinlich in demselben "kleinen Bau von Holz" nahm Haushofer den letzten Abschied von seiner Mutter. Das Bild des Hauses, das in der Stille der Berge steht, ist ihm unvergesslich geblieben. 
Außer seinen Erinnerungen an die Heimat hatte er nur ein Glas Honig, das er anscheinend mit ins Gefängnis gebracht hatte:

ein Glas mit Honig hab ich mir gespart. so viel an Heimat ist mir nun geblieben. 21

Im Duft dieses Honigs liegt der Zauber und die Kraft, Haushofer aus den "grauen Ecken" seiner Zelle hinauszuziehen und ihn wieder in die Umgebung. seiner geliebten Bergheimat $\mathrm{zu}$ versetzen. Sicher ist ein Glas mit Honig als Erinnerung seiner Heimat sehr wenig, aber symbolisch enthielt es für den Dichter alles, was ihm an der Heimat lieb war. 


\section{$\underline{\text { Reisen }}$}

Die bildliche Darstellung mancher Moabiter Sonette ist durch die Erinnerung an seine vielen Reisen geprägt. Während seiner Tätigkeit in Berlin als Assistent Pencks, eines der bedeutendsten deutschen Geographen und Eiszeitforschern, als Herausgeber der "Zeitschrift für Erdkunde" und als Generalsekretär derselben Gesellschaft, vermochte er viele Reisen zu unternehmen. Zwischen 1925 und 1931 reiste er durch Nord- und Südamerika, durch Sowjetrußland bis zur Wolga, durch die Türkei, Nordafrika und ganz Europa. 22. Schon als junger Mann kannte er die Welt wie nur wenige Menschen.

Die Erfahrungen seiner Reisen und deren starke Eindrücke auf ihn, bringt er selbst zum Ausdruck in dem folgenden Vers:

An Meer und Ländern hab ich viel durchstreift, hab gleich Odysseus in bewegten Jahren von Menschenart und Menschenleid erfahren, allmählich ist mein Bild der Welt gereift.23

Die Erinnerungen an diese Reiseerlebnisse brachte er zum vollen, reichen Ausdruck in seinen dichterischen Werken. Viele seiner früheren Gedichte schildern diese Erlebnisse. In den Moabiter Sonetten findet man sie nicht als Hauptthema, sondern mehr als metaphorische Elemente. Nur das Sonett "Miyajima" kann als eine reine Schilderung

$$
\begin{aligned}
& 22_{\text {Hildebrandt, S. } 48 .} \\
& 23_{\text {Haushofer, Moabiter Sonette, S. } 68 .}
\end{aligned}
$$


eines Reiseerlebnisses gelten.

$$
\text { Miyajima }
$$

Ein Tempeltor, durch das die Wasser ziehn, am Strand geschwungner Steinlaternen Reihe, uralter Kiefern leis durchrauschte Weihe und Rehe, die vor keinem Menschen fliehn.

An plätscherndem Gewässer steigt empor den Hang ein Pfad von Stufen, im Verblühn von reichster Wildnis: Rot und Gold und Grün. Aus Abendwolken bricht die. Sonne vor...

Der Gipfel - goldne Nebel ringsherum und Inseln ungezählt, Gebirge, Meer aus lichter Tiefe schimmern Segel her.-

Du hohes Eiland, stilles Heiligtum in Japans blauer See, bewahre rein durch alle Zeiten deiner Geister Sein! 24

Aber auch hier erscheint im zweiten Terzett die warnende, lehrhafte Tendenz, die in den meisten Sonetten vorherrscht. 


\section{Freundschaft und Liebe}

Von seiner Jugend an war Albrecht Haushofer ein Einzelgänger, obwohl er viele Freunde und Bekannte hatte. Aber sein ganzes Leben lang hielt er sich zurück, als hätte er Angst, sich durch irgendeine Schwäche zu verlieren. Sein Bruder schreibt, "Il eut des amis, bien sur. Mais ses amitiés ignoraient la gaieté de la jeunesse, elles étaient incertaines, souvent il y mit fin avec un singulier désespoir. Plus tard, il nomma quelques-uns de ses élèves des amis, mais ils ne le furent pas réellement. De très bonne heure, il se sentit vieux. 25

Bis zum 14. Iebensjahr war der kleine Junge fast immer allein mit seiner Familie. Bis zu dieser Zeit bekam er Privatunterricht zu Hause. "Die Tatsache, daß Albrecht bis zu seinem vierzehnten Lebensjahr Hausunterricht genoß, erklärt sein Einsamkeitsstreben. Durch diesen Unterricht war Albrecht seinen Altersgenossen an Bildung weit überlegen, die genaue Kenntnis Japans, die ihm sein weitgereister Vater vermittelte, war für einen Jungen seines Alters staunenswert." 26

Man könnte vielleicht sagen, daß er zu spät die Bedeutung der Freundschaft begriffen hat. Heimpel hat über ihn in Die halbe Violine geschrieben:

${ }^{25}$ Heinz Haushofer, "Souvenirs sur mon frère Albrecht," Verger. Revue des Spectacles et des Lettres en Allemagne occupee. $\frac{1}{1 . J a h r g a n g, ~ N . ~ 5 . ~(k e i n ~ D a t u m) ~ S . ~} 24$.

26PreiB, S. 24. 
52

Er kam... in die Klasse [siebte Klasse des Gymnasiums] reich an Bildung, arm an Waffen, denn ihm waren die Spielregeln fremd, nach denen man sich unter Pennälern behauptet. Er war wie ein fremder Vogel in einem Hühnerhof: er wurde gemieden und hackte, nur um AnschluB zu gewinnen. 27

In diesen ersten Schuljahren fand auf Anregung der Eltern - wahrscheinlich weil sie ihrem zurückgezogenen Sohn helfen wollten, sich seiner Einsamkeit u entziehen - im Hause Haushofers ein regelmäßiges Schülertreffen statt. Während dieser Begegnungen hielten die Studenten Vorträge über verschiedene Themen, sei es, daß sie von einer Reise berichteten, eine Dichtung interpretierten oder ein Gespräch über ein geschichtliches Thema führten. 28

In dieser Zeit entstand Haushofers erste Dichtung Abend im Herbst. Das Drama ist ein Gespräch von jungen Freunden. Einer nach dem anderen wendet sich von dem geistig Überlegensten des Kreises ab, weil er zu hochmütig, zu beharrlich in seiner vom Leben her nicht zu rechtfertigenden Abgeschlossenheit erscheint. Das Werk besitzt hohen autobiographischen wert und spiegelt das Denken und Empfinden des jungen Dichters wider. Die schwermütige Natur sowie die intellektuelle Reife des jungen Haushofers ist deutlich erkennbar.

Den Frieden will ich heut mit der Natur, Verstehen will ich, wo Verstandensein.

27 Heimpel, S. 225.

$28_{\text {Hildebrandt, S. } 44 .}$ 
Unmöglich ist und sich den Menschen weigert. Hab' Dank, beseeltes All, für Glück und Leid! Denn was du unter deinen Schicksalsgaben An großem Leid vielleicht vergessen hast, An kleinen Leiden holst du's mühsam nach, Und darum dank' ich dir die große Gabe!... Die Stille lebt.... Ich will zu Bette gehn... Der Sternenfriede senkt sich auf die Welt Und adelt alles, was im Tag verging..."29

Kurz nachdem Haushofer nach Berlin umgezogen war, erlebte er seine erste und vielleicht seine einzige Iiebe. Das Mädchen war eine lebensbejahende intelligente Tochter eines bekannten Forschers. Vielleicht fürchtete Haushofer, daß die Totalität und Vitalität dieser Persönlichkeit zu viel von ihm verlangen würde; vielleicht ahnte er, daß. er sich an ein solches Wesen ganz und gar verlieren könnte; oder vielleicht fühlte das Mädchen, daß Albrecht ihr einen Teil seines innersten Wesens entzog, um nicht durch sie der Wissenschaft untreu zu werden. 30 Vielleicht fürchtete Haushofer auch einfach, im weiblichen Netz gefangen zu werden. Aus welchen Gründen auch immer, trennten sich die zwei jungen Menschen.

Hildebrandt schreibt über ein anderes Mädchen, das Haushofer später kennenlernte: "Außer seiner Jugendliebe war dies die einzige Frau, die in seinem Leben eine bedeutende Rolle gespielt hatte." 31

In einem der vollkommensten und schönsten Sonette

29 Albrecht Haushofer, Abend im Herbst, Unveröffentlichtes Manuskript. (in Prei BY Dissertation) S. 117.

$30_{\text {Preis, }}$. 32.
$31_{\text {Hildebrandt, S. } 176 .}$ 
erinnerte er sich an die zwei Frauen seines Lebens.

\section{Traumgesicht}

Du. hast so lange mich im Traum gemieden,

$\mathrm{Du}$ früh Verblichne. Heute warst $\mathrm{Du}$ da, so jung, so unzerstört, so seltsam nah wie damals, als zum erstenmal wir schieden. Wie loderten in jener Nacht die sterne, Wie schien die Welt voll Glück. Wie lang ist's Wie wurden Dir die jungen Jahre schwer. Wie trieb es mich hinaus in alle Ferne. Nun prüfst Du mich im Traum. Es ist kein Schmerz und keine Trauer mehr in ihm gewesen. Du nickst und flüsterst. Bist Du nun genesen?Ich liege still. In Ruhe schlägt mein Herz. Geblieben - ist ein Dank. Der Dank soll ziehn hinauf $\mathrm{u}$ Deinem Grab im Engadin. 32

Die ähnlichen Umstände dieser zwei Erlebnisse - die beiden Mädchen sind jung und kurz nach der Auflösung der Bindung gestorben -verschmolzen in Haushofers Erinnerung, zu einer Einheit. Eva PreiB meint, 1 -8 des Sonetts wenden sich eindeutig an eben dieses Mädchen seiner ersten Neigung, wëhrend sich die Zeile 14 mit der Erinnerung an das Grab im Ingadin auf die spätere Liebe berieht. 33

Während seiner ersten Berliner Jahre kam Haushofer in einen der geistigen Kreise Berlins, den sogenannten "Montagstisch." Zu diesem Kreis gehörten Männer und Frauen aus den politischen, künstlerischen, wissenschaftlichen und Iiterarischen Ieben Berlins.

32 Haushofer, Moabiter Sonette, s. 83. 33 PreiB, S. 33. 
Man darf daneben die Männer der Verschwörung - seine Gefährten - nicht vergessen, wenn man über die Bekanntschaften Albrecht Haushofers spricht.

Und schließlich gehören die Schüler Haushofers zu seinem Freundeskreis. Es ist interessant, daß drei seiner Studenten auch seine Biographen waren: Rainer Hildebrandt schrieb, "Wir sind die Ietzten", Rolf Italiaander gab eine feinsinnige Schilderung von Haushofer in Besiegeltes Leben, und Walter Stubbe trug zu dem Schrifttum über Haushofer einen Essay bei. Hildebrandt schildert seinen Lehrer so:

Dieser Mann, der in so jungen Jahren schon so viel Funktionen besaß, hatte stets Zeit für seine Schüler. Er saB unter ihnen und sprach davon, was hinter den Kulissen des Nazi-Regimes geschah und versuchte, den Vorgang in seinem ganzen politischen Zusammenhang zu verdeutlichen. Oder er erzählte von Weltreisen, von Begegnungen mit großen Männern, oder er versuchte, das Lebensgefühl fremder Völker zu erklären.34

Über einen Schülerfreund, Wolfgang Hoffmann-Zampis, schrieb Haushofer auch das rührende Sonett, "Der Freund."

Der Freund

Du Toter, denkst Du des Gefährten auch? Heut war mir wieder zwischen Traum und Wachen, als hört ich Dein vertrautes, tiefes Iachen, als fühlt ich an der Wange Deinen HauchDu hast so viel geschaut, gespürt, geahnt, hast früh mit früher Wandlung Dich verbündet, hast mir noch dunkle Mühsal streng verkündetist nun auch mir der Weg zum Strom gebahnt?

Ich bin bereit $\mathrm{zu}$ bleiben und $\mathrm{zu}$ gehen. Es leben nicht mehr viele, die mich halten... 
die Toten sind die tieferen Gewalten...

Ich fühle Dich im Boot als Fergen stehen,

ich fühle Deine Hand sich grüßend heben-

Du schweigst... soll ich Dir folgen? Soll ich leben?35

Wieder, wie in dem Sonett "Traumgesicht," erscheint

dem Dichter die Erinnerung an den geliebten Freund, der auch sein Leben so früh verloren hatte, in einer Traumwelt. Dazu vergleiche man den Vers aus "Der Freund" "Heut war mir wieder zwischen Traum und Wachen" mit dem ersten Vers aus "Traumgesicht:" "Du hast so lange mich im Traum gemieden." Es ist bedeutungsvoll, daß er an die höchstpersönlichen Erfahrungen seines Lebens nicht im Rahmen der wirklichen welt, sondern in dem der unrealistischen, phantasievollen Traumwelt denken wollte.

Sein Freund, Wolfgang Hoffmann war 1942 auf der Krim gefallen. Von allen Verlusten, die Haushofer in seinen letzten Lebensjahren zu ertragen hatte, traf ihn der des jungen Freundes am schwersten. Es istmöglich, daß er in diesem Tod sein eigenes Schicksal ahnte. "Ist nun auch mir der Weg zum Strom gebahnt?" fragt er den toten Freund. In diesem Gedicht spürt man die ganze Qual und den Schmerz, die Haushofer in dieser Zeit ertrug. Alles, was er liebte und verehrte, alles was für ihn in diesen letzten Tagen als wichtig und bedeutungsvoll galt, war vergangen. 
Einige Gedanken aus einer Gefëngniszelle

Die Sinnlosigkeit des Krieges mit seiner Vernichtung, seinen Schmerzen und seinen Verlusten sind Themen vieler Sonette. Das Sonett "Rattenzug," bei dem man an die Volkssage "Der Rattenfänger von Hameln" denkt, stellt die Armee dar, als "ein Heer von grauen Ratten," das von einem Pfeifer geführt wird. Ausführlich beschreibt der Dichter die Bewegungen der Rattenarmee, die alles, was in ihrem Weg steht, frißt und vernichtet. Aber wie in der Volkssage wurde das "Rattenheer" ahnungslos und hilfIos in die Vernichtung getrieben.

\section{Rattenzug}

Ein Heer von grauen Ratten friBt im Land. Sie nähern sich dem Strom in wildem Drängen. Voraus ein Pfeifer, der mit irren Klängen zu. wunderlichen Zuckungen sie band.

So ließen sie die Speicher voll Getreidewas zögern wollte, wurde mitgerissen, was widerstrebte, blindlings totgebissenso zogen sie zum Strom, der Flur zuleide...

Sie wittern in dem Brausen Blut und Fleisch, verlockender und wilder wird der Klangsie stürzen schon hinab den Uferhang-ein schriller Pfiff - ein gellendes Gekreisch:

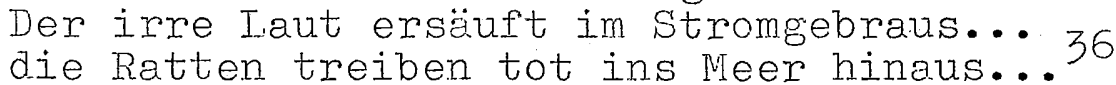

In manchen Sonetten klingt ein tief pessimistischer Ton an. In einem wird die Nenschheit "Tiger-Affen" genannt, denn sie ist "dem Affen gleich an mörderischer Kraft." Wenn die Menschheit dem Dichter auf solches Niveau ge- 
sunken zu sein scheint, ist es verständlich, daß Verstand für ihn keinen Sinn mehr hat.

Was half es, daß der wägende Verstand

die Rechnung führte bis zum letzten Schluß!

Der Wahn begreift nur, was er fühlen muß.

Der Wahn allein war Herr in diesem Iand.

In Ieichenfeldern schließt sein stolzer Lauf, und Elend, unermeßbar, steigt herauf. 37

Nachdem dieser Wahn seinen sinnlosen Kurs gelaufen ist, sieht Haushofer, daß am Ende "Nur Schutt und Asche, werden Zeugen sein." 38

Obwohl der Dichter sein Bedauern über die materiellen sowie geistigen Verluste der Traditionen seiner Epoche häufig ausdrückt, kommt nur einmal echte Bitterkeit über sein eigenes Schicksal zum Ausdruck. Mit der Erinnerung an Beethovens "Fidelio," in dem die Gefangenen mit heroischem Willkommen vor dem Gefängnis empfangen werden und wo Gutes über Böses siegt, fragt sich Haushofer, ob es keine Gerechtigkejt gibt. In den ersten Zeilen erzählt er die Geschichte der Oper und erreicht den triumphierenden Höhepunkt in der elften Zeile, um dann plötzlich die ganze Stimmung des Sonetts zu ändern:

Im Leben gibt es diese Töne nicht.

Da gibt es nur ein lähmendes Verharren.

Danach ein Fenker, ein Im-Sana-Verscharren. 39

37

37 Ibid., s. 61.

38 Ibid., S. 49.

39 Ibid., $\$$. 30. 
Während' solch einer hoffnungslosen Gefangenschaft, in der man nicht weiB, wielange man noch leben wird, rücken Menschen einander näher als selbst nach jahrelanger Bekanntschaft.

...spür' ich durch die wände das Beben vieler bruderlicher Hände. 40

Haushofer fühlte ein tiefes Mitleid mit Kameraden, die seinen Zustand miterlebten.

Ich bin der erste nicht in diesem Raum, in dessen Handgelenk die Fessel schneidet an dessen Gram sich fremder Wille weidet. 41

Aber sein Mitleid gilt nicht nur den Mitgefangenen, sondern auch den zahllosen Menschen, die ungewollt und hilflos: Opfer des Krieges wurden. Mit Verständnis und Gemüt äußert er dieses Mitleid in dem Sonett über seine Wächter, die ja auch Häftlinge waren.

Die Wächter

Die wächter, die man unsrer Haft gestellt, sind brave Burschen. Bäuerliches Blut. Herausgerissen aus dex Dörfer Hut in eine fremde, nicht verstandne welt.

Sie sprechen kaum. Nur ihre Augen fragen zuweilen stumm, als ob sie wissen wollten, was ihre Herzen nie erfahren sollten, die schwer an ihrer Heimat Schicksal tragen. Sie kommen aus den östlichen Bereichen der Donau, die der Krieg schon ausgezehrt. Ihr Stamin ist tot. Ihr Hab und Gut verheert. Noch warten sie vielleicht auf Lebenszeichen. Sie dienen still. Gefangen-sind auch sie Ob sie's begreifen? Morgen? Später? Nie?42
${ }^{40}$ Ibid., s. 11 .
${ }^{41}$ Ibid., $\mathrm{S} .11$.
${ }^{42}$ Ibid., S. 19. 
Zum Thema seines Mitgefühls gehört auch das Sonett, "Der Arzt." Während der ersten Wochen seiner Gefangenschaft, wurde Haushofer von einem Arzt gepflegt, der ebenfalls Häftling war. Dieser Arzt hatte einen Schlüssel gestohlen, mit dem er Haushofers Fesseln öffnen konnte. Er zeigte Haushofer, wie er es zu machen habe, um sich selbst die Fesseln wieder anzulegen. Dieser Arzt war es, der Papier und Bleistift besorgte, damit Haushofer seine ersten Sonette, als er noch gefesselt war, schreiben konnte. 43 Diesem gütigen Menschen widmete Haushofer das folgende Sonett.

Der Arzt

Wenn nicht - von allen Lastern dieser. Weltam meisten blasses Gift im Neid sich fände, so neidet ich dem Arzt die milden Hände, mit denen er die Hilfe rings bestellt. Sein Mahl ist kalt, daß keiner von den Kranken die Wärme misse. Halten andre Rast, so wandert er und pflegt, und keine last ist ihm zu groß, mag er vor Bürde schwanken. Des Heilens Gnade ward ihm zugeteilt. Von seinen Händen strahlt ein heller Schein in vieler Zellen dumpfes Grau hinein. $B$ evor die rechte Stunde mir enteilt, erbitt ich, ohne Scheu, mit klarem Ton, 44

Aus des Dichters Sehnsucht nach Freiheit erstehen manche der schönsten und lyrischsten Gedichte. Diese Sehnsucht nach Freiheit drückte er in Natursymbolen aus. Die Berge und Täler seiner geliebten Alpen, das Meer und die

43 Hildebrandt, S. 192.

${ }^{44}$ Haushofer, Moabiter Sonette, s. 45. 
Vögel symbolisieren die Freiheit, die Geborgenheit und die Einsamkeit, nach denen er sich sehnte.

Nordwestwind...

...drängt in meine Zelle. Kann es sein -

die Nase prüft - . Ist's nicht nur eine spur

von Salz in dieser Luft? Wär's Täuschung nur?

Und plötzlich rauscht das Meer zu mir hinein. 45

In einem zärtlichen Sonett "Spatzen" freut er sich

über den Besuch zweier Spatzen. Mit lyrischem Ton spricht

der Dichter vom Schnäbeln des "Spatzenfräuleins" und des.

"Spatzenritters." Aber in dem Sextett kehrt er in die Wirklichkeit seiner Lage zurück:

Wie seltsam ist es, ungehemmte Leben

in Fesseln voller Frage nahzustehn -

ob mich die flinken, schwarzen Augen sehn?

Sie schauen fort. Ein Tschipp, ein Flügelheben,

der Eisenrost ist leer. Ich bin allein.

Wie gerne möcht ich bei den spatzen sein...46

Tod heiBt für Haushofer auch Befreiung von der

quälerischen Sehnsucht nach Freiheit. In dem melancholischen Sonett "Val Tuoi" erinnerte er sich an einen schönen.Tag, den er in den schweizerischen Alpen verbracht hatte. Seine Sehnsucht nach den Bergen und aer Freiheit, die sie bedeuten, wird zur Todessehnsucht. Auf dem Gipfel eines Berges möchte er sterben. Der Leser spürt auch in diesem Sonett die traurige Erkenntnis des Dichters, daß solch schöne, glückliche Stunden in einem Menschenleben nur sehr selten sind.

$$
\begin{aligned}
& { }^{45} \text { Ibid., S. } 86 . \\
& { }^{46} \text { Ibid., S. } 26 .
\end{aligned}
$$




\section{Val Tuoi}

Vom hohen Gipfelglück des Piz Buin ins Val Tuoi zog unsre Wanderspur durch weicher, bachdurchrauschter Almen Flur, durch Arvenwald hinab ins Engadin.

Ich fühlte, wie die Zeit des Glücks entrann, so flüchtig wie des Morgens klare Luft, so flüchtig wie der Matten süßer Duftich sah zurück auf Eis und Fels und sann: Wär's nicht ein schöner Schluß für meine Tage, dort oben muid in weichen Schnee zu sinken, zum letztenmal der Sonne Schein zu trinken und einzuschlafen ohne Wunsch und Klage?Wir wandern fort. Ich denke still zurück an Val Tuoi, an Gipfel, Tod und Glück.4? 
Selbstuberwindung und Innere Wandlung des Dichters

In den vorhergehenden Seiten dieser Arbeit wurden die Moabiter Sonette von verschiedenen Standpunkten dargestellt: als Ausdruck der Weltanschauung des Dichters, als autobiographische Einblicke in sein Leben und als Widerspiegelung einiger seịner Gedanken während seiner letzten Lebensmonate. Aber es bleibt noch ein wichtiger Aspekt der Sonette, der untersucht werden muß.

Die letzten Monate im Gefängnis führten den Dichter zu einer Prüfung seines eigenen Lebens. Und die Moabiter Sonette sind Zeugnis dafür, daß er trotz seiner wiederkehrenden Verzweiflung eine innere Wandlung erlebte, die ihn vorbereitete, seinen Tod mit neuer sicherheit anzunehmen.

Die Eisenketten, die er tragen mußte, lehrten ihn, daß es andere Fesseln gibt, die sowohl binden als auch schwerer zu lösen sind. Über diese Fesseln schreibt er:

Sie haben mich gelehrt, daß andre Ketten zu dulden wie zu lösen schwerer sind: Begierden, Wiinsche, die sich aus dem Kind in Mannestrotz und Greisenhärte retten: 48

Den größten Teil seines Lebens verbrachte Haushofer im Kampf gegen ein verhasstes Regime. Zuerst warnte er nachdrücklich vor dem sich nähernden Übel; später nahm er an den Bestrebungen zum Umsturz des Regimes teil. Es ist kein Wunder, daß ihn ein Gefühl äuBerster Hoffnungslosigkeit überwältigte, als diese Versuche scheiterten. 
64

Aus dieser tiefen Verzweiflung, welche aus den folgenden Versen spricht, begann seine innere Wandlung.

An der Schwelle

Die Mittel, die aus diesem Dasein führen, ich habe sie geprüit mit $A u g^{\prime}$ und Hand.

Ein jëher Schläg - und keine Kerkerwand

ist mächtig, meine seele zu berühren.

Bevor der Posten, der die Tir bewacht, den dicken Klotz von Eisen sich erschlösse, ein jäher Schlag - und meine Seele schösse hinaus ins Jicht - hinaus in ferne Nacht.

Was andre hält an Glauben, wïnschen, Hoffen, ist mir erloschen. Wie ein Schattenspiel scheint mir das Leben, sinnlos ohne ziel.

Was hält mich noch - die schwelle steht mir offen. Es ist uns nicht erlaubt, uns fortzustehlen, 49 mag uns ein Gott, mag uns ein Teufel quälen. 49

Die Frage, ob er sterben oder leben soll, hat der Dichter sich schon in dem Sonett "Der Freund" gestellt. Die Gedanken, die in dem ersten Terzett des Gedichtes oben geäuBert werden, ähneln dem Vers "Es leben nicht mehr viele, die mich halten..." aus "Der Freund" in Stimmung und Gefïhl.

Die Gedanken der letzten drei Zeilen "An der Schwelle" sind besonders wichtig, wenn man sie als das erste Kennzeichen der Wandlung des Dichters deutet. ob es der Wille zum Ieben war, der ihn vor Selbstmord schützte, oder ob sein Zögern aus irgendeinem religiösen Gefüh] ("Es ist uns nicht erlaubt, uns fortzustehlen," s) stammte, ist hier nicht wichtig.

Wenn man diese Verse als den Ausgangspunkt von Haus- 
65

hofers Abwendung von der äußeren Welt sieht, wenn man sie als den Anfang seiner inneren Selbstprüfung, die ihn zu einer neuen Gemütsruhe führte, interpretiert, finden die Moabiter Sonette ihr echtes Wesen in der poetischen Dokumentation des Strebens eines Menschen, sein eigenes Schicksal mit Sicherheit und Tapferkeit anzunehmen: Man darf die Sonette, die bis jetzt in dieser Arbeit dargestellt wurden, als verschiedene Stationen seines Lebens auffassen - Stationen, die ihm seine Selbstüberwindung zu gewinnen halfen.

Ein wichtiges Sonett in dieser Wandlung ist "Schuld". Ob er schuldig oder unschuldig in den Augen des bestehenden Gesetzes war, ist nicht wichtig. Seine Schuld ist eine persönlich gefühlte Schuld, die daraus resultiert, daß er, trotz seiner Erkenntnis des Übels des Regimes, nicht genug getan hatte, daß er nicht stark genug und wirksam genug gemahnt hatte, daß er zu lang mit der Tat gezögert hatte. In der Einsamkeit seiner Zelle, frei von aller Eitelkeit, wuchs sein Verantwortungsgefühl, und er äußerte seine eigene Schuld, für die es keinen irdischen Richter gab.

\section{Schuld}

Ich trage leicht an dem, was das Gericht mir Schuld benennen wird: an Plan und Sorgen. Verbrecher wär' ich, hätt' ich für das Morgen des Volkes nicht geplant aus eigner Pflicht Doch schuldig bin ich onders als ihr denkt, ich mußte friher meine Pflicht erkennen, ich muRte schärfer Unheil Unheil nennen- 
mein Urteil hab ich viel zu lang gelenkt...

Ich klage mich in meinem Herzen an:

Ich habe mein Gewissen lang betrogen,

ich hab mich selbst und andere belogen -

ich kannte früh des Jammers ganze Bahn -

ich hab gewarnt - nicht hart genug und klar!

"Der Schierlingsbecher" gehört auch zu diesem Schuldmotiv. Hier verehrt Haushofer den großen griechischen Philosophen Sokrates, der stark genug war, sich für seinen Glauben und für das, was er als Recht erkannte, zu opfern. Haushofer bedauert es, daB ihm diese Tapferkeit fehlte.

Der Schierlingsbecher

Man will noch in Athen den Ort bezeugen, wo Sokrates gewartet haben soll, bis jene Frist der frommen Feste voll, um sich dem tödlichen Gesetz zu beugen. Ich ging vorüber an der dunklen Schwelle, den Blick zum Parthenon emporgewandt, und übersah, von lichtem Glanz gebannt, den Todesbecher in der Tageshelle. Nun reut mich, daß ich dort vorüberging. Es hätte sich geziemt, ins Knie zu sinken und wissend von dem Schierling mitzutrinken.

Es war ein Großer, der sich unterfing, des eignen Staates blinden Mordgewalten als Opfertier die Treue so zu halten.51

Der Wissenschaftler in ihm hatte sein Ieben lang um ein Höchstmaß äußerer und innerer Freiheit gekämpft, um sich behaupten zu können. In diesem Kampfe mußte er fremde Einflüße notgedrungen ausschalten, um sich selbst nicht in anderen Menschen zu verlieren. Unter der wis-

${ }^{50}$ Ibid., S. 48.

51 Ibid., S. 16. 
senschaftlichen Abgeschlossenheit hatte er seinem persönlichen Leben sowie seinen Freundschaften nur einen ganz beschränkten Bezirk einräumen dürfen.

Aber das heißt nicht, daß er kein Gefühl für die Leiden seiner Mitmenschen besaß. Im Gegenteil, es ist wahrscheinlich ein Zeichen dafür, daß er zu empfindlich war, daß er ein zu großes Herz besaß. Rolf Italiaander sagt:

Er war mit einer großen Herzenswärme und Herzensgüte begabt. Diese, vermischt mit viel (fast femininer) Melancholie, waren sogar so stark, daß er sich, um nicht Sentimentalitäten zum Opfer zu fallen, bei seinen politischen Aufgaben unbedingt mit eiskaltem Sarkasmus abschirmen mußte...Albrecht Haushofer lehrte mich, daß [Sarkasmus und Ironie] sich in einem Mann auch als Schutz gegen zuviel Herz, gegen zuviel Gemüt entwickeln können. 52

In den Monaten der Gefangenschaft des Dichters und durch dessen Selbstprüfung spürt der Leser, daß er die Wichtigkeit menschlicher Bindungen erkannt hat. Die zwei Gedichte "Traumgesicht" und "Der Freund" weisen auf dieses Bewußtsein hin. Es wird auch im Sonett "Kami" deutlich, daß er in der Erinnerung an diese vielleicht zu weit von sich gehaltenen Freundschaften eine neue Kraft fand, die ihm Trost und Hilfe in diesen schweren Monaten gab.

\section{Kami}

Vor vielen Gräbern hätt ich mich zu neigen, um nach des fernen Ostens tiefem Brauch noch Dank zu sagen, eh der eigne Hauch

\footnotetext{
52 Italiaander, s. 20.
} 
hinüberweht - nun muß ich's aus dem Schweigen der Zelle tun. Die Seele loszubinden von aller Umwelt hab ich längst gelernt, $\mathrm{zu}$ lenken, wenn sie suchend sich entfernt.Die Toten helfen ihr, die Bahn zu finden.

Die Toten wissen die besondren Zeichen:

Sie bleiben stumm für Seelen, die begehren, und stumm für Seelen, die noch nicht verehrendoch lassen sich die Toten gern erreichen, wenn man, befreit von aller wïnsche Weben,
nur kommt, um ihnen Lebensdank zu geben. 53

Es gibt kaum einen Beweis, auf Grund dessen man Haushofers Beziehung zum Christentum erklären könnte. Es fehlen christliche Motive in den Dramen, und in den Sonetten ist es nicht leicht festzustellen, ob der Dichter den christlichen persönlichen Gott meint, wenn er das Wort "Gott" gebraucht. Obwohl die inneren Werte, die er in seinen werken darstellt und deren Verlust er bedauert, Werte sind, die wir meistens mit den Worten "westliche christliche Tradition" kennzeichnen, kann er sie natürlich annehmen, ohne sich selbst als Christ zu verpflichten. Ferner soll der Leser sich hüten, im Glauben des Dichters an eine historische Gerechtigkeit, an eine kosmische Notwendigkeit und an eine moralische Weltordnung, wie sie in dieser Arbeit dargestellt werden, den christlichen Glauben zu sehen. 54

Jedoch gibt es keinen Zweifel, daß der Dichter im Sonett "Qui resurrexit" eine bewußte Bejahung des

\footnotetext{
${ }^{53}$ Haushofer, Moabiter Sonette, S. 84. ${ }^{54}$ Hoffmann, S. 177.
} 
Christentums ausdrückte. Dieses Sonett ist sicher mehr als ein Versuch, den berühmten Isenheimer Altar, "Auferstehung Christi" von Mathias Grünewald lyrisch wiederzugeben.

Es ist auch wichtig zu bemerken, daß in diesem Gedicht die Bejahung des Christentums als etwas Neues, als etwas, das ihm nur die Gefängniserfahrung bringen konnte, erscheint. "Doch keines wollte ganz in mir bestehen."

Die letzten drei Verse bestätigen, daß Haushofer - ein neues Vertrauen gefunden hat, daß der Tod nicht unbedingt das Ende bedeutet.

\section{Qui Resurrexit}

In tausend Bildern hab ich Ihn gesehn. A's Weltenrichter, zornig und erhaben, als Dorngekrönten, als Madonnenknaben,doch keines wollte ganz in mir bestehn. Jetzt fühl ich, daß nur eines gültig ist: Wie sich dem Meister Mathis Er gezeigtdoch nicht der Fahle, der zum Tod sich neigtder Iichtumflossne: dieser ist der Christ. Nicht Menschenkunst allein hat so gemalt. Dem Grabesdunkel schwerelos entschwebend, das Haupt mit goldnem Leuchten rings umwebend. Von allen Farben geisterhaft umstrahlt, noch immer Wesen, dennoch grenzenlos, führt Gottes Sohn empor zu Gottes Schoß.55

Die letzte Bestätigung von Haushofer innerer Wandlung findet man in einer Reihe von Sonetten. Menschliche Wünsche und Begierden, Ehrgeiz und Eitelkeit versinken. Die Ketten, mit denen sie binden, sind gelöst; 
Bin ich von ihnen freier als ich war, so dank ich diesem letzten halben Jahr.56

In der letzten Untersuchung erscheinen sie nur als ein kleiner Teil - sogar unwichtiger Teil - eines größeren, bedeutungsvolleren Ganzen.

Wir sind ja beide, Mensch und Mücke, nichts als kleine Schatten eines großen Iichts. 57

Dieses neugewonnene Verständnis wird in dem Sonett "Wandlung" zusammengefaßt.

\section{Wandlung}

Von dem, was uns in jungen Jahren band, an Wunsch und Wort in menschlichen Gestalten, wie wenig hielt den tödlichen Gewalten im letzten Prüfen unsrer Seele stand!

Wie vieles, was wir früher kaum gesehn, ist heute nah. mit ungeheurem Wirken: Wir nähern uns den heiligen Bezirken, von denen scheu wir nun in Ehrfurcht stehn...

Wie Gold und edle Steine sich im Sand verborgen halten, bis der sand verweht und ihr Gewicht allein im Sturm besteht, So hebt sich nun aus allem lauten Tand das Unvergängliche. Das Ich wird still, Wenn Es in ihm schon leise beten will...58 
V: DIE FORM DER MOABITER SONETTE

UND EINIGE BESONDERHEITPN DES STILS

Nach der Untersuchung des Inhalts der Sonette lohnt es sich, einen kurzen Blick auf die äußere Formdie Struktur der Sonette = zu werfen sowie auf einige Besonderheiten des Stils hinzuweisen.

Form war für Albrecht Haushofer sehr wichtig. Sein Bruder schreibt darüber: "Parceque lui-meme [était] très sensible, il prisait très fort la forme...Briser la forme lui semblait péché mortel. Il se mêfiait de la création spontanée, il avait besoin du temps." 1 Man kann ohne besondere Mühe erkennen, wie stark bei Haushofer der Formwille mit dem Intellekt verhaftet ist und wie stark die innere und die äuBere Form zu einem organischen Ganzen verschmolzen sind.

Ohne Ausnahme sind die Moabiter Sonette gleich in Metrikschema und Reimbau.

Die Sonette sind in fünffüßigem Jambus geschrieben. Wenn ún / ge duŕd / und Hófe / nungs lós / ig kéit

Die Reime sind durchwegs von größter Reinheit unter Vermeidung unschöner Gleichklänge. Der Leser erkennt sofort, mit wie viei Sorgfalt der Dichter die Auswahl seiner Reimwörter traf.

Auch veränderte der Dichter seinen Reimbau nicht. Das Reimschema der Oktave ist ein umschlingendes, vier-

\footnotetext{
${ }^{1}$ Haushofer, Heinz, S. 26.
} 
reimiges:

abba/cd.dc

In der Auswahl des Reimbaus des Sextetts verwendet Haushofer ein Schema, das nicht häufig in der sonettdichtung der deutschen sprache vorkommt.

$$
\text { eff / egg }
$$

Die RegelmäBigkeit der Metrik und des Reimbildes ist umso erstaunlicher, wenn man das Original-Manuskript sieht. Die Sonette sind mit einer schönen, knappen Handschrift auf fünf Bogen Papier - acht Sonette pro Seite mit Mintenstift eng geschrieben. Sie zeigen fast keine Korrekturen.

Natürlich ist es möglich, daß Haushofer die Sonette zuerst auf anderem Papier entworfen hat. Jedoch findet man keine Erwähnung in der Iiteratur, daß es so war. Wenn aber das Manuskript die Umfassung dieser Sonette darstellt, muß man die Sorgfalt anerkennen, mit der der Dichter seine Sonette zuerst durchdachte und dann niederschrieb.

Die Reimanoranung der Verse: $9-12$ (eff/e), wie bei den beiden Quartetten, im umschlingenden Reim mit dem folgenden Reimpar am Schluß des Sonettes wird den Leser on die Form des englischen sonettes erinnern. Der Dichter verstärkt diese Beziehung zum Shakespearsonett durch die Verwendung des Paarreims in den Schlußversen, wo er das inhaltliche Kriterium einiger sonette erhärtet 
und betont. Dafür ist das folgende Sonett ein gutes Beispiel:

\section{Nächtliche Botschaft}

Noch andre Botschaft rieselt aus der Nacht in meines Wesens kaum bewuBte Schichten. im Wellengang von Tönen und Gesichten wird mir von Toten letzter Sinn gebracht. Zu deuten das Gefühlte, bleibt versagt. Die Toten rufen uns auf eigne Weise mit Klängen wie von einer sternenreisenur eines weiß ich, da der Morgen tagt. So wenig in den stoffgebundnen Reichen, seit Schöpfertum im Sonnenkreis begann, ein Körnchen Staub verlorengehen kann, so wenig darf ein seelenhauch entweichen. Wohin er weht, wenn er dem Leib entflieht die Frage scheut, wer keine Grenze sieht.

Auch von diesem Gesichtspunkt aus betrachtet, erweist es sich, daß er in der eigenwilligen Form seiner Sonette eine Art Synthese zwischen der musikalisch-schwingenden Art der italienischen Sonette und dem gedanklicherregenden Aufbau der englischen sonette erstrebt und erreicht, um eine in dieser Art ganz ihm eigene, interessante sonettstruktur zu formen.

Eva Preiß vermerkt, im Gegensatz zu anderen deutschen Dichtern verwendet Haushofer in seinen Sonetten sehr gern den männlichen Reim, mit dessen Hilfe er gelegentlich in den Quartetten, hauptsächlich aber in den lerzetten die Härte des Schicksals charakterisiert. 3 Die im Deutschen äußerst seltene Verwendung ausschlieBlich männlicher Reime im Sonett taucht bei Haushofer zweimal auf: in den

\footnotetext{
Haushofer, Moabiter Sonette, s. 12.

3 Preiß, S. 146.
} 
Sonetten "Mutter" und "Schwanenring." Diese gehören nicht nur inhaltlich unmittelbar zusammen, sondern bilden auch einen Höhepunkt im Ausdruck persönlichster Empfindung des Dichters.

Die Moabiter Sonette erfüllen die Forderung des italienischen Sonetts nach strenger Trennung von Oktave und Sextett. Iediglich in einem Sonett, "Paola i Francesca" ist das erste Terzett syntaktisch vom letzten Vers der Oktave abhängig. Es ist ein reizvoller Widerspruch, daß gerade dieses Sonett, das thematisch einen Höhepunkt italienischer Literatur darstellt, als einziges diese Forderung der italienischen Sonettform durchbricht.

Auch die Quartette sind mit Ausnahme einiger Sonette syntaktisch voneinander getrennt. Die Ausnahmen entspringen sicher nicht der Unfähigkeit des Dichters, die beiden Quartette durch einen Punkt zu trennen. Vielmehr beabsichtigt er durch diese Satzverschleifung "eine besondere musikalische und sachliche Betonung der ersten Worte des zweiten Quartetts. Somit kommt das Enjambement dem ernsten getragenen Gehalt der Sonette zugute, weil der Übergang von einer Zeile oder gar strophe zur anderen unmerklich vor sich geht." 4 Manche Sonette weisen auf die Musikalität des Dichters hin. Durch häufige Verwendung der Alliteration und

$$
4 \text { PreiB, S. } 146
$$


gleichklingender Vokale verbindet der Dichter die inhaltichen und formalen Ilemente der Dichtung. Sein Ohr ist besonders empfindlich für Alliteration, und. seine Iiebe dazu ist dadurch erkennbar, daB er sie so oft benutzt; zum Beispiel:

"Wlenn Hagen Tronjes Trotz als Treue galt." und.

"In Strahl und Schwingung zu gemessnem Spiel" Als Beispiel gleichklingender Vokale gilt der folgende Vers:

"wie düster flühn die dunklen Miythen auf," Die bildiche Darstellung der Moabiter Sonette wird durch historische oder literarische Vergleiche und Natursymbole statt der Verwendung poetischer Metaphern bereichert. Ein starkes Kennzeichen aller Gedichte Haushofersist, daB jedes Bild von der Gestalt her direkt in die intellektuelle Form des Gedankens übergeht. "Man wird Wïhe haben, ein Bild zu finden, dessen Deutung nicht tief in die Mittelbarkeit des Intellektes und der überlegenden Vernunft hineingreift. Es gibt kein einziges, das auch nur in einer Zeile ein Naturerlebnis wiedergäbe, das frei von krisenbewußter Sentimentalität wäre. Die Erkenntnis, daß es für ihn keine Zukunftserlebnisse mehr geben werde, gibt ihrn von der Gegenwart und von der Vergangenheit weiten Abstand. " 5

Seine Verwendung der lietapher ist, wie gesagt, sel-

$$
{ }^{5} \text { Ibid., S. } 123 .
$$


ten. Die Erklärung dafür liegt vielleicht in der folgenden Definition der Aufgabe der Metapher:

die Hauptaufgabe der Metapher besteht darin, abstrakte und irrationale Elemente auf dem Weg über subjektives Empfinden in der Dichtung zu lebhafter Vergegenständlichung zu bringen. Aus diesem Grund ist es wohl verstëndlich, daß jemand im Vollgefühl des Iebens und der eigenen Freiheit und Unabhängigkeit in der Wahl seiner Bilder und Symbole ganz anderen Gesetzen gehorcht, als wenn er in einer Gefängniszelle sitzt und jeden Augenblich gewärtig sein muß, plötzlich hingerichtet zu werden. Kaum ein Bauelement der Iyrik ist so sehr der Subjektivität verhaftet wie die Metapher. 6

Jedoch sind die Metaphern an den wenigen Stellen, wo der Dichter sie verwendet, schön und wirksam, wie das folgende Beispiel zeigt.

Im frïhen Morgen stand ich einst am $\mathrm{Nil}$ und sah das erste rosenrote licht derr Bau der Pyramiden, Schicht um Schicht, umrieseln, bis es in die Gärten fiel...?

Haushofer verwendet oft drei Interpunktionszeichen, die dem Leser sofort auffallen: Gedankenstrich, Anführungszeichen und Satzellipse (...).

Durch die Verwendung des Gedankenstrichs isoliert der Dichter häufig ein Hauptwort, ein Verb oder sogar einen ganzen Teil eines Satzes vom Reste des Satzes. Meistens sind es sehr starke, gefühlsbetonte: Wörter; Zum Beispiel: "gebunden", "lodern", "ein schriller Pfiff", "gefangen", und "Gericht." Diese Verwendung der Interpunktion verstärkt die Kraft des Wortes visuell sowie

\footnotetext{
6rid., s. 118.

7 Haushofer, Moabiter Sonette, S. 65.
} 
rhythmisch.

Bei elf Sonetten benützt der Dichter Anführungszeichen, um eine Dialogwirkung zustandezubringen. In "Persische Legende" sind sogar acht der vierzehn Zeilen "zitierter" Dialog. Während diese syntaktische Behandlung manchmal in der Dichtung sehr wirksam sein kann, fragt man sich, ob sie im Sonett ihre gemäße Verwendung findet. Die Regelmäßigkeit und Knappheit der Sonettform scheinen die lose Dialogform auszuschließen.

Daher sind die Sonette, die in Form eines prosa-artigen Dialogs erscheinen, arm an ästhetischer und künstlerischer Vollkommenheit.

Die Verwendung einer Ellipse kann eine der wirkungsvollsten syntaktischen strukturen sein, um eine elliptische Wirkung zu erreichen. Durch die Ellipse vermag ein Dichter, einen "Schwundeffekt" zu bewirken. Er kann dadurch andeuten, daß seine Gedanken abgeschlossen sind. Er kann damit häufig etwas sehr Ziartes ausdrücken. Haushofer benützte die Satzellipse sehr oft und erreichte manchmal eine sehr schöne und bedeutungsvolle Wirkung, wie in den Sonetten "Mutter" und "Rattenzug." 


\section{VI: WARUMT SONETTE?}

Unter den frïheren Gedichten Albrecht Haushofers erscheinen nur zwei Sonette, "Gesang der alten Burg" (1932) und "Die Schatzträger" (1938). Man fragt sich, warum er diese strengste Gattung der Dichtung aussuchte unò. warum er glaubte, daß diese Form besonders dafür geeignet sei, seine letzten dichterischen Gedanken auszudrücken.

Die Antwort auf diese Fragen liegt in der Persönlichkeit des Dichters und auch in der Natur und den Forderungen der sonettform selbst.

In seinem umfassenden Buch, "Das Sonett, Gestalt und Geschichte, schreibt Walter Mönch: "Das Sonett ist die gegebene Form für den Geistmenschen, den Denker, der, wie Schaefier sagt, im Zustand einer Leidenschaft eine Befeverung seines Wesens und somit auch der Verstandeskrä.fte verspürt.. "1 1

Bei einer Formuntersuchung an den Moabiter Sonetten wird nachzuweisen sein, wie die innere Haltung des Dichters und seine überlegende, logisch-strenge Gedankenführung' gepaart mit verhaltener Tiefe des Gefühls seiner Selbstïberwindung gerade im Sonett den adäquaten Ausdruck finden. 2

\footnotetext{
Walter Wönch. Das Sonett, Gestalt und Geschichte. (Heidelberg: F.H. Kerle VerIag, 1955) S. 36.

${ }^{2}$ Gudehus, S. 102.
} 
Johannes R. Becher schrieb in "Das poetische

Prinzip" :

Wenn man sich vergegenwärtigt, daß die Einheit des Wahren, des Guten, des Freien und des Schönen und zugleich die Einheit des Dichters und des Denkers in einem räumlich und zeitlich so beschränkten Gebilde, wie es das sonett darstellt, erreicht werden muß, so wird man die Sonettkunst als die höchste aller Dichtungsarten bezeichnen dürfen, als die Form, worin die Dichtung aller Zeiten und Völker sich gleichsam übertreffen und sich selbst überstiegen hat.3

Die Sonettform selbst hat auch etwas fast Mystisches an sich, das Haushofer und andere Dichter locken mag. Es ist auffällig, daß das Sonett in Zeiten der gröBten Erschütterungen und des Chaos besonders häufig erscheint. Albrecht Haushofer war nicht der einzige Dichter, der während dieser schweren Zeit des nationalsozialistischen Regimes Sonette schrieb. Unter der Iiteratur der sogenannten "Inneren Emigration" findet man Sonette von Rudolf Hagelstange (Venezianisches Credo) und Reinhold Schneider (Sonette, Die letzten Tage, u.a.), um nur zwei der bekanntesten Dichter zu nennen.

Vielleicht enthalten die folgenden Zeilen von Johannes R. Becher das Wesen der ordnungschaffenden Qualität des Sonetts, die Haushofer bewußt oder unbewußt lockte.

...wenn Form nur ist, damit sie sich zersprenge, und Ungestalt wird, wenn die Totenwacht die Dichtung hält am eignen rotenbett, alsdann erscheint, in seiner schweren strenge

3Johannes R. Becher. Das poetische Prinzip.

(Berlin: Aufbau Verlag, 1957), $\frac{19}{\mathrm{~S} .423 .}$ 
und wie das Sinnbild einer Ordnungsmacht als Rettung vor dem Chaos: das Sonett. 4

Diese Zeilen schrieb Becher, nachdem er mit vielen Formen der Dichtung experimentiert hatte. SchlieBlich kehrte er als "Rettung von dem Chaos" zu der strengen Form des Sonetts zurück. Hier dürfen wir die Zeilen in einer weiteren Bedeutung verstehen.

In einer Situation völliger Lösung aller vorherigen Bindungen, unter der beständigen Auswirkung des Chaos und dem Eindruck immer never Demütigungen fand der klare Formwille des Dichters seinen Ausdruck in der Strenge des Sonetts. ${ }^{5}$ Hhnlich ist es wenn J.S. Bach im Gefühl des nahenden Todes mit seiner "Kunst der Fuge" die Beherrschung der höchsten, reinsten und zugleich kompliziertesten musikalischen Form erstrebte, und wie Mozart, wissend um seine tödliche Krankheit, in der Overtüre zu seiner letzten Oper, "Die Zauberflöte", sowie im Werk selbst immer wieder die strenge Fugenkomposition verwendete.

Ein weiteres Kennzeichen der Sonettform, das Haushofer sicher stark interessierte, ist die Ähnlichkeit des Sonetts mit dem Drama. Wie im klassischen Drama erkennt man im Sonett "die Bewegung von Expansion und Kontraktion, eine Steigerung zum Höhepunkt. Häufig findet

\footnotetext{
${ }^{4}$ Johannes R. Becher. Wiedergeburt, Buch der Sonette. (Leipzig: Insel Verlag, 1947) S. 6.

${ }^{5}$ Gudehus, s. 117.
} 
man erst im zweiten Terzett den konzentrierten Teil eines Sonetts, während alles Vorangehende nur Vorbereitung, Zuspitzung auf den Moment der höchsten Spannung ist. " 6

Dieses dramatische Element verwendet Haushofer sehr oft mit gutem Erfolg in vielen seiner sonette:. Haushofer war sein ganzes Leben lang sehr streng an Form gebunden. In den Begriffen des Maßes und der Form erkannte er die Weltordnung. Sein Bemühen hatte immer wieder der Bewahrung der Form gegolten, und so ist es wohl kein Zufall, daß er die strenge Sonettform wählte, die in der deutschen Sprache mit ihren verhältnismäßig geringen Reimmöglichkeiten im Vergleich zu den romanischen Sprachen nur schwer zu meistern ist.

Sein Bruder sagte, daß er vielleicht durch die Verwendung einer strengen und hemmenden Form irgendwie eine sicherheit gefunden habe. ${ }^{7}$ Immer kämpfte er gegen sich selbst, um sich zu beherrschen, um nach den Regeln der Vernunft und des Verstandes zu leben. Die Vermutung des Bruders stimmt um so mehr, wenn man an die Unsicherheit denkt, die Haushofer in seinen persönlichen Verhältnissen zeigte. Innerhalb des Bereiches der Wissenschaft und des Wissens fühlte er sich sicher, aber er blieb "in der Suche nach menschlichem Kontakt im Kreise der Freunde

$6_{\text {Mönch, S. } 37}$

7 Heinz Haushofer, Persönliches Gespräch, Hartschimmelhof, den. 4. März 1967. 
82

und Schüler oft linkisch, tappend und unsicher..." 8

Während jener schwersten Tagen seines Lebens, suchte er wahrscheinlich eine Sicherheit durch Ordnung und Maß in der strengen Form des Sonetts.

Das Sonett ist "im Reiche der Lyrik die Gegenform zu Iied und Gesang," schreibt Rudolf Ibel. "Es

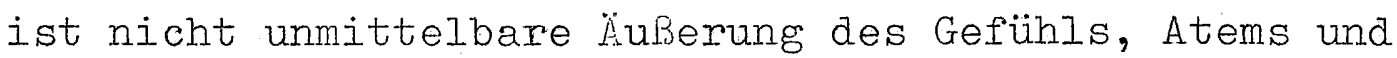
Bildes, es fordert bereits von der Form her vor allem Geist und Reflexion, kunstvolle Knüpfung, Paraphrase: und Variation von Gedanken, die Gedankenfolge." 9 Es genügt, nur einen oberflächlichen Blick in das Lęben des Dichters zu werfen, um zu sehen, daß er als Dichter und als Mensch konsequent zu vermeiden suchte, seine Gefühlswerte allzu deutlich auszudrücken. Deshalb behauptet Eva Preiß, daß eine Gesamtschau auf das Werk des Iyrikers nicht übersehen werden darf und, daß der offenbar so kühle Vordergrund seines Schaffens nur die Sublimierung eines leicht verwundbaren Herzens darstellt. ${ }^{10}$ Nur in einigen sonetten läßt der Dichter seine Gefühle unverhüllt ausströmen. Man wird sich hier an "Mutter," "Der Freund" und "Val Toui" erinnern.

\footnotetext{
Walter Stubbe. "Seinen Gedanken," in In Memoriam Albrecht Haushofer. (Hamburg: Verlag Friedrich Oetinger, 1948) S. 26.

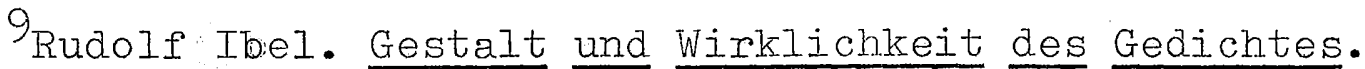
(Passau: bei Heimeran, Gesamtherstellung Passavia, 1964, ), S. 50 .

$$
{ }^{10} \text { PreiB, S. } 109 \text {. }
$$
}


Auch liegt innerhalb des Bereiches des Sonetts eine didaktische Qualität. "Darum ist das Sonett auch so häufig auf dem Übergang vom Iyrischen zum Didaktischen zu finden, da es, ähnlich wie das Epigramm in seiner antiken Form, oftmals eine Mischung beider Elemente in sich schließt."11

Haushofer strebte immor danach, eine Wirkung auf seine Schüler, seine Freunde, sowie auf die Politik auszuïben. Diese lehrhafte Tendenz ist deutlich sichtbar in den Moabiter Sonetten.

Schließlich ist das sonett die meistgebrauchte Gattung, wenn man eine Gedichtsammlung von endlosen Variationen von Themata verschiedenster Natur, eines unaufhörlichen "Kreises," um einen Mittelpunkt schreiben will. Seit frühester Zeit tritt das Sonett in Zyklen oder Sequenzen auf. Albrecht Schaeffer schreibt in einem Aufsatz. "Über das Sonett":

Ein Gedanke kommt niemals allein; Assoziation ist das Wesen des Denkens. Keinen Menschen gibt es deswegen, der nur ein Sonett gemacht hätte; jedes regt zumindest ein zweites an, und gemeinhin erscheinen sie in Zyklen, in Gruppen. 92

Diese Sonettryklen schaffen eine Art Romane- Romane der Liebe, der tragischen welterfahrung, der politischen und sozialen Leidenschaft der Menschheit und Völkerund Kulturgeschichte und Romane über philosophische, meta-

\footnotetext{
11 Mönch, S. 36.

12 Ibel, S. 50 .
} 
physische und religiöse rhemen. 13 Die großen Sonett-Dichter schrieben Sonettzyklen; Petrarca, Camoes, Lope de Vega, Shakespeare, Barrett-Browning und Rilke.

Die Moabiter Sonette erfiilen sicher die Anforderung eines Sonett-Romans. Innerhalb der Variationen der Themen kehren sie immer wieder zu dem Dichter selbst und zu seinem letzten Versuch, sich zu überwinden, zurück.

Es ist nicht zu verwundern, daß nicht alle Moabiter Sonette vollendete Meisterwerke sind. Die Form des Sonetts stellt ungewöhnlich hohe Anforderungen und verlangt ein selten erreichtes Gleichgewicht von Form und Gedanken, Spannung und Ruhe. Selbst in einer Sonettsammlung, die unter den besten Umständen geschrieben wird, findet man selten, daß jedes Sonett vollendet ist und alle Ansprüche der Form erfüllt sind. Deshalb müssen die äuBeren und inneren Bedingungen im Auge behalten werden, unter àenen die Moabiter Sonette entstanden sind. Ob der Dichter selbst die Sonette für vollendet hielt, bleibt eine unbeantwortete Frage. Tatsächlich schrieb er in den letzten Wochen keine Sonette mehr, sondern begann ein neues Drama, Thomas Morus. Charles Hoffmann meint, daß die Sonette nicht für die Veröffentlichung geschrieben wurden. Seine Meinung begründet er damit, daß Haushofer seine zwei friheren Gedichtsammlungen nur als Privataruck veröffentlichte. ${ }^{14}$ Dr. Eeinz Haushofer sagte

$$
\text { 13 Miönch, S. 37. 14 Hoffmann, S. } 58 .
$$


aber Im Gespräch, daB sein Bruder sicher die Moabiter Sonette hätte veröffentlichen lassen. 15

Haushofer war zuerst und vor allem Lehrer, und die Sonette sind voll didaktischer Töne. Hätte er geglaubt, daß seine Dichtung einen rationalen Einfluß auf die zukünftigen Generationen ausüben würde, daß diese letzten Gedichte irgendwie zu einer vernünftigen Welt führen würden, dann ist die Meinung des Bruders richtig.

Man findet in den Sonetten Beispiele, wo die Sonettform offensichtlich ein Hindernis für den Dichter zu sein scheint.

Manchmal spürt der Leser, daß einige wörter und sogar Zeilen nur den Anforderungen der Form dienen und wenig mit dem Inhalt zu tun haben. Solche Verse sind meistens die letzten einer strophe oder eines sonetts. Es scheint in diesen Fällen, als hätte der Dichter schon gesagt, was er zu sagen hätte, als er sah, daß ihm noch ein Vers fehlte. ${ }^{16}$

Die letzten arei Zeilen von "Lawinen" zum Beispiel sind schwach, da sie die vorhergehenden Zeilen des Sonetts nicht betonen. Die Verse "Vermessenheit im Guten oder Bösen-/ ich büße den Versuch, sie aufzuhalten," scheinen dem Ieser keinen logischen Zusammenhang miteinander zu haben, sowie reine notwendige Verbindung mit dem Rest

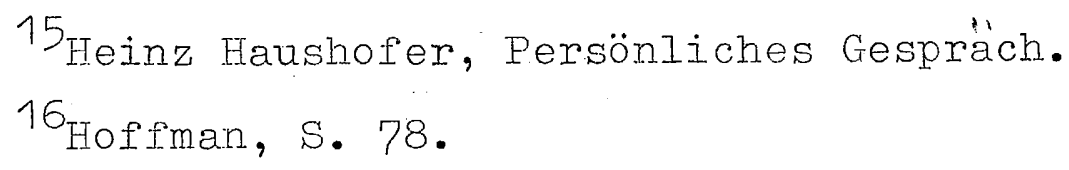


des Gedichts darzustellen. Auch das letzte Terzett des folgenden Sonetts ist im Zusammenhang mit den vorhergehenden Versen überflüssig. Nach dem Abschluß des elften Verses nützt das letzte Terzett nichts, und deshalb schwëcht es das ganze Gedicht.

Der Schierlingsbecher

Man will noch in Athen den Ort bezeugen, wo Sokrates gewartet haben soll, bis jene Frist der frommen Feste voll, um sich dem tödlichen Gesetz zu beugen. Ich ging vorüber an der dunklen Schwelle, den Blick zum Parthenon emporgewandt, und übersah, von lichtem Glanz gebannt, den Todesbecher in der Tageshelle. Nun reut mich, daß ich dort vorüberging. Es hätte sich geziemt, ins Knie zu sinken, und wissend von dem Schierling mitzutrinken.

Es war ein GroBer, der sich unterfing, des eignen Staates blinden Mordgewalten als Opfertier die Treue so zu halten.17

Auch hätte der Dichter die Themen einiger Sonette besser in einer anderen dichterischen Form behandelt. Ein Beispiel dafür ist das Sonett "Acheron." Das Gedicht blieb ein Fragment verschiedener Gedanken. Vielleicht hätte der Dichter in anderer Versform das Thema besser behandeln können.

Der Denker Haushofer scheint den Dichter Haushofer manchmal zu stören. Er ist zu beschwert von der pülle der Gedanken und Reflexionen, um sie ohne MiBklang der strengen Architektur des Sonetts anzupassen. 18

17 Haushofer, Moabiter Sonette, s. 16.
$18_{\text {Felix M. Wassermann. "Ein Denkmal des Ewigen }}$ Deutschlands: Albrecht Haushofer "Moabiter Sonette, "Monatshefte für deutschen Unterricht, deutsche Sprache und Iiteratur. XI, Nr. 6 (Oktober 1948), S. 313 . 
Noch eine Schwäche der Moabiter Sonette sehe ich darin, daß sie wirklich nur verständlich sind im Zusammenhang mit dem Zyklus und wenn man etwas von dem Lebenslauf des Dichters weiß. Manche Sonette, die innerhalb des Zyklus gut und zweckmäßig sind, scheinen. ohne näheren Erklärungen fast unverständlich.

Albrecht Schaeffer spricht über eine dreifache Parallelität, die die innere Form des Sonetts verlangt.

Dem ersten Quartett laufe ein zweites Parallel, wie dem ersten Terzett das zweite; die zweite Strophe der Oktave wiederholt, ausbauend, erweiternd, vertiefend den Gehalt der ersten. Mit den Terzetten setzte das Neue ein, eine Ausdeutung des ersten Gehaltes, den wiederum das zweite Terzett vertiefe. Ein Bljck von hier aus zurïck, zum Eingang erweise die Erscheinung der dritten Parallele, in dem nunmehr der Gehalt der ersten und zweiten Gedichthälfte sich womöglich bis zur Identität verschmölzen und das Sonett zu Einheit machten.19

Es ist erstaunlich, daß der Dichter es unter den schweren Umständen fertiggebracht hatte, diese: Parallelität der inneren Form des sonetts in fast jedem Sonett zu erreichen. Die Beispiele gelungener Sonette, in denen der Dichter die Anforderung und das Verlangen der äußeren sowie der inneren Form des Sonetts erfüllt, überwiegen. 
VII: EIN VERGIEICH DER SONEITE MIT FRÜHEREN GEDICHTEN

AuBer den Moabiter Sonetten gibt es zwei wenig bekannte Sammelbände von Gedichten Albrecht Haushofers, die leider nur in Privatdrucken erschienen sind. Die erste Gedichtsammlung. Richtfeuer erschien im Jahre 1932. Sechs Jahre später sammelte er einen zweiten Band und ließ ihn unter dem Titel Gastgeschenk drucken.

Im Gegensatz zu den Moabiter Sonetten benützte der Dichter in den früheren Gedichten eine Anzahl verschiedener Rhythmen und Strophen-Bauformen. Über allen Gedichten liegt das Gesetz strenger Rhythmen, die jedesmal neu gewähltes, bewußtes Oranungsprinzip verkörpern. Die frühe Neisterschaft, mit der er seine Dichtungen schrieb, um jeden Gedanken und jede Stimmung in der ihnen gemäBen Form zum Ausdruck zu bringen, ist erstaunlich. 1 Inhaltlich entstanden die Gedichte meistens auf seinen großen Auslandsreisen, worauf die Titel hinweisen. ("Isle de France", "Am Yellowstone See", "Süaliches Meer", "Peking", "Auf der Fahrt," u.s.w.). Auch drücken die Gedichte, wie später die Sonette, Ưberlegenheit, Einsamkeit, Ausweglosigkeit und ein gewisses Maß von Pessimismus aus.

\footnotetext{
Felix M. Wassermann. "Fin unbekanntes Denkmal deutscher Dichtung in der Krisenzeit der DreiBiger Jahre des XX. Jahrhunderts: Zwanzig Gedichte Albrecht Haushofers," The Journal of English and Germanic Philology. IV, No. 1 (January, 1956) S. 29.
} 
Die Naturschilderungen, die Erinnerungen, die Bilder sind niemals rein lyrische Darstellungen. Jedes Bild wird zum Symbol; immer sind Bild und Erlebnis -mit philosophischer Reflexion verbunden. Das ist deutlich in dem folgenden Gedicht aus der Sammlung Richtfeuer.

$$
\text { Am Yellowstone-See }
$$

Stille silberblaue Fläche, die im späten Abend träumend Zu den purpurgrauen Bergen weit ins Ungekannte schwindet, Deren kühles Fluten, leise an den flachen Ufern schäumend,

Sich dem Schweigen einer dunklen Wildnis alleemach verbindet,

Stille silbergraue Fläche, drin die lichten Wellenringe, Kaum geboren, sich verbreiten in die ungekannte FerneFühlst wie wir du? Oder spürtst du nur den Wind, die Vogelschwinge, Wald und Berge und das weiBe Leuchten deiner klaren sterne?

Jeder Leser wird "sofort, ohne vom Leben Albrecht Haushofers auch nur etwas gehört zu haben, aus der Bildwahl erkennen, daß den Gedichten ein durchdachtes Erlebnis zugrundeliegt. Die Wirkung einer neuen Landschaft auf den Menschen Albrecht Haushofer bleibt immer dieselbe, nämlich ein Vergleichen und Abstrahieren und ein Loslösen des vergänglichen äußeren Kleides, um zu den ewigkeitsgültigen Werten zu gelangen." 2

In den 1932 erschienenen Gedichten ahnt man die starke Verbindung, die er mit der Vergangenheit fühlte. Sogar in diesen früheren Gedichten findet man kein Zeichen von jugendlichem "Sturm und Drang." Schon damals fühlte er, daß es seine Pflicht war, sich als "Kämpfer der 
Vergangenheit": zu widmen. Hierher gehören die Symbole der alten Burg und der alten Eiche. Die Burg, die wir nur als Ruine sehen, symbolisiert die überdauernden Werte einer Tradition. So sieht Haushofer auch die Eiche, die lang noch stehen wird, nachdem die jungen Birken schon ihre Blätter verloren haben.

Gesang der alten Burg

Von meinem Felsen schau ich in die Zeit, Ruine nennt mich, wer vorüberhastet -Sie fürchten, was an Daver in mir lastet, Weil doch aus ihnen nur die Leere schreit -Seit nur dem Nutzen dieses Volk sich weiht, Seit dieser Lande tiefes Werden rastet, Seit nirgendwo mehr Schöpferisches glastet, Bin ich ein Kämpfer der Vergangenheit. Ich rage fest, ich bin von altem Blut. Geschlechter bauten mich zu eignem Ieben. Und ill der Boden selbst nicht stürzend beben, So weiB ich, daB ich stolz auf dieser Erde, In eigener Gestalt, geformter Glut, Die neuen Menschen überdauern werde.

Diese Stimmung setzt sich in dem Gedicht "Der Ahnenring" fort. Die Verehrung und die nicht immer leicht zu tragenden Pflichten der Tradition der Vergangenheit sind das Thema dieses Gedichts.

Der Ahnenring

"Graugoldner Onyxreif an meiner Fand, Der sich zu mir aus altem Erbe fand Darein vergangne Zeit ihr Wappen schnitt: Des jungen Pulses Blut, fühlst au ihn mit?" "Ich fühle nichts. Wer Ahnensiegel trägt, Muß wissen, daß er späte Züge prägt; Und wissen muß, wem solche Schrift gedeiht, Daß er sich dienend einer Kette reiht."

Man wird sich daran erinnern, daß Haushofer das Thema eines Sonetts in diesem selben Siegelring fand. 
Aber in "Schwanenring" fühlte der Dichter weitaus weniger die Verbindung mit der Vergangenheit als vielmehr die Einheit mit den Geschlechtern der Zukunft, die er im Bild des Ringes symbolisiert.

Das Wort "Herbst" spielte für Haushofer eine wichtige Rolle. Es taucht in eben dem ersten dramatischen Gedicht Abend im Herbst auf. In diesem einzigen Wort liegt der Schlüssel zu Haushofers philosophischer Überzeugung, daß seine Epoche sich ihrem Ende nähert. Vielleicht darf man sagen, daß er die früheren Gedichte während des "Herbstes" seiner Epoche schrieb, während die Moabiter Sonette im tiefsten "Winter" dieser Epoche geschrieben wurden.

Sonnenuntergang, Abenddämmerung und Herbst stellen für den Dichter ein Symbol des nahenden Endes dar.

$$
\text { Am Bodensee: }
$$

Ruderschlag um Ruderschlag, Strahlt empor ein frischer Tag.

Gipfel strahlt im Sonnenkuß, Daß die Sonne wandern muß. Gipfel leuchtet mittaghell-. Mittagklarheit wandert schnell. Gipfel glüht im Abendschein, Birgt in sich das Rot hineinNiedersank ein müder Tag, Ruderschlag um Ruderschlag.

In diesen früheren Gedichten liegt der Zauber von Wind und Wellen, von Licht und Duft und Klang. Welch ein überfeines Erfassen des Verklingens und Verdämmerns der Herbstlandschaft, des letzten Aufleuchtens der Alpen- 
gipfel, der Abendstimmung vor Notre Dame bis zum letzten Schweigen des Unsagbaren und der in Raum und Zeit verlorenen Ferne! 3

Schweigen

Die letzten Dinge sind dem Wort versagt. Du kannst sie kaum an ihren Tränen messen, Die Glück und Trauer ihnen stumm entpressen In dunkler Nacht. Sie trocknen, wenn es tagt.

Die melancholische Stimmung des Dichters sowie sein stëndiges Denken an den Tod kommen nicht zuerst in den Moabiter Sonetten zum Ausdruck. Aber während die früheren Gedichte "von einer sanften Melancholie getragen sind, die sich hauptsächlich aus dem Schicksal des geschauten Iandes ergibt, zeigen die Sonette eine ganz andere Art von Melancholie, die man fast als romantisches Fernweh. eines gefesselten Menschen bezeichnen könnte. " 4 Zwar gibt es Landschaftsbilder in den Sonetten, aber man empfindet eine tiefe Resignation, als ob Haushofer in der Iinsamkeit seiner Zelle nur zu gut wïBte, daß diese Fernträume unerfüllbar sind.

Wie gerne zög ich ostwärts auf die Fahrt! Wer ist so wenig Tor, daß̉ er sich nimmer Verlor an eines Traumes fernen Schimmer...5

In beinahe allen von Haushofers Dichtungen spürt man, daß er sein frühes Ende geahnt hat. Die Melodie des Todes klingt aurch alle Dichtungen, nicht nur die

\footnotetext{
Wassermann, Monatshefte, LV, No. 1, (Januar, 1956.) S.27.

4 Preiß, S. 96.

5 Haushofer, Moabiter Sonette, S. 85.
} 
überlegene Todesbereitschaft der Moabiter Sonette.

In "Herbstgast" spiegelt sich sogar eine romantische Sehnsucht nach dem Sterben wieder. Die Müdigkeit eines. schön gezeichneten sterbenden Schmetterlings symbolisiert die Todesbereitschaft des noch nicht 30 jährigen Dichters, der sich schon so alt fühlte.

\section{Herbstgast}

Es flog ein Schmetterling mir auf die Hand, Ein schöner Falter, schwarz, mit rotem Band, Mit muidem Flattern, als ich heut im Kahn Durchfurcht den see auf spiegelnd blauer Bahn. Die Sonne schien. Ich fuhr zum Uferrand Und brachte sorgsam meinen Gast zu Land. Ich legt ihn auf ein rotes Buchenblatt Und merkte wohl, er war zum sterben matt. So ließ ich ihn...Er klappt die Flügel...ruht... Umspielt von milder Himmelsstrahlen Flut. Ich rudre weiter in den Herbst hinein. Und doch - wie schön muß heut das Sterben sein!

Durch die gesamte Dichtung kehrt das Thema des Wunsches nach Zurückgezogenheit und Entfernung von der Welt wieder. Er sehnte sich immer danach, sich dem Wissen um des Wissens willen, sich dem Geist um des Geistes willen zu widmen. Er gab dieser Sehnsucht Ausdruck durch Dichtung. Immer symbolisieren die Berge für ihn den Ort die-.. ser Zurückgezogenheit, dieser Entfernung.

Der Abschied des Alten

Er stand am letzten Paß des Reichs, Der Wächter wehrte die Schranke. "Wer über die Berge wandert Und prifte die Welt---"

"Ich kenne die Welt von oben und prüfe sie nicht." "Wer über die Berge wandert und suchte die. Welt_-_"

"Ich kenne die welt von außen und suche sie nicht." 
"Wer Uiber die Berge wandert Und liebte die Welt--"

"Ich kenne die Welt von innen

Und hasse sie nicht."

Da gab der wächter die Schranke frei.

Der Alte verschwand in den Bergen.

Die Gestalt des Alten in diesem Gedicht, der an den Grenzen des Reiches ohne Wunsch und Haß in der menschenfernen Einsamkeit der Berge verschwindet, ähnelt der Gestalt des Mönches in Chinesische Legende. Unter den dramatischen Gestalten Haushofers ist der Mönch eine der interessantesten. Ihm gehört das Dasein der letzten Schau, wo Wille und Sinn eins werden, die höchste Form des kontemplativen Lebens, die nicht mehr Flucht aus der Welt, sondern Überwindung der Welt bedeutet. 6 Diese Figur stellt den Philosophen, den Wissenschaftler in Haushofer dar. Diese geistige Haltung, die Haushofer in der Gestalt des Mönches darstellt, rang immer mit der des Zensors. Der Zensor stellt die Seite von Haushofer dar, die politische Pflicht und Staatsdienst verkörpert.

Mönch:

Der eine ging gemeBnen Schrittes fort

Und suchte Dienst im Reiche der Gestalten, In jenen Ante, wo Gerechtigkeit

Im Kampfe liegt mit Süchten der Gewalt, Der andere $\mathrm{zog}$ in unbekannte Fernen

Und suchte, zwischen Sein und Nichtsein irrend, Auf langer Wanderschaft den großen Sinn. Am Ende nahmen den zur Milde Reifen Die Tore der Erleuchtung bergend auf-?

\footnotetext{
S. $317 \mathrm{f}$.

$6_{\text {Wassermann, Monatshefte, XIII, No. 7, (November 1950) }}$

7 Haushofer, Chinesiches Legende, s. 52.
} 
Später in den Sonetten taucht das. Thema in dem Gedicht "Tibetisches Geheimnis" wieder auf. Wieder stellen die fernen hohen Gipfel der Welt symbolisch den Ort dar, "wo Geistes-Wunder...schon hohes Können ist" und "wo das kleine Ich" sich "ins große Du hinein" verwandelt. Die Gedichte der späteren Sammlung Gastgeschenk zeigen noch stärker die Auseinandersetzung des Dichters mit seiner Zeit und Umwelt. Diese Gedichte schrieb er während der Zeit seiner aktivsten wissenschaftlichen und politischen Tätigkeit. Wie in den Dramen, die auch größtenteils während dieser Zeit geschrieben wurden, gebrauchte er sein dichterisches Talent, um zu mahnen und vorauszusagen, was kommien werde.

In einem Gedicht "Wagenlenker" ist das Bild des Wagenlenkers wie in prophetischer Schau gezeichnet, der im eignen Siegestaumel das Opfer vergißt, das seinem Triumph gebracht wurde.

"Du fühlst den Jubel seine Schwingen regen Du hast vergessen, daß Dein Gegner starb!"

Dariber hinaus spiegeln sich bei den anderen Gedichten der Sammlung von 1938 schon in den Überschriften die Eindrücke des Krieges wider und werden in einer solch beklemmenden Erlebnisdichte gestaltet, daß die Nähe des großen Weltbrandes deutlich wird.

Wohl glüht ein Herbst in golden-reifer Farbe Von Wirbelstirmen rings umdroht Wer atmet noch den Hauch der vollen Garbe, Wenn schon die Flamme zucht und springt und loht? 
Das Hektische der Kriegsvorbereitungen bleibt dem Sehenden nicht verborgen.

Blitze zucken durch die Narrenwelt!

Siehst Du,wie der wirre Lauf sich steigert?

Weißt Du, wann der letzte Tempel fällt?

Drehend steigt das Brandgewölk empor!

Allmählich wächst Haushofers Auseinandersetzung mit seiner Zeit und Umwelt und wird zum zentralen Thema seiner Dichtungen. Die Gedichte entwickeln sich von der noch weitgehend "reinen" persönlichen Iyrik der Sammlung Richtfeuer zu der unverkennbar typischen Gegenwartsnähe im Gedichtband Gastgeschenk bis zur universalen Auseinandersetzung mit Zeit und Umwelt in den Sonetten. Gleichzeitig wächst sein Pessimismus. Er fühlt, daß er mitten in einer sterbenden Epoche lebt, und daß alles, was er ehrt und liebt, seinem Ende entgegengeht. 
VIII: ALBRECHT HAUSHOFER ALS POLITISCHER DICHTER

Whe man Albrecht Haushofer als "politischen Dichter" kennzeichnen kann; fragt man sich, was der Begriff "politischer Dichter" bedeutet.

Meint man damit, daß der Dichter nur die politischen Ereignisse seiner Zeit als Thema für seine Dichtung nimmt? Frast jeder gewissenhafte Dichter wird von den Ereignissen in seiner Umwelt mehr oder weniger beeinfluBt. Ist es die stärke, mit der die politische Atmosphäre auf den Dichter wirkt, und der Grad, in dem die politischen Ereignisse in seinem Werk zum Ausdruck kommen, wodurch ein sogenannter "politischer Dichter" sich von jedem anderen Dichter unterscheidet?

Oder soll der Begriff bedeuten, daß der Dichter durch sein Schaffen auf die politischen Ereignisse seiner Zeit EinfluB ausüben möchte? Ist es eine Frage des Wirkenwollens und einer unmittelbaren Verflechtung mit dem Strom des politischen Lebens? Ist ein politischer Dichter einer, der von Verantwortungsgefühl getrieben wird, der die Themen seiner Gedichte in dem politischen Leben sucht und findet und seine Iandsleute zum Aufstand oder zur Unterstützung aufruft?

Der Begriff schließt alle diese Aspekte ein; liegt aber die Betonung nicht darauf, daB er eine Wirkung durch 
seine Dichtung entweder auf die politischen Führer oder auf seine Mitbürger ausüben möchte.

Adolf Grimme nannte Albrecht Haushofer einen politischen Dichter, weil er "um das missionarische Amt des Dichters wußte." 8

Für Haushofer war der Dichter ein "Rufer in die Zeit," sagt Adolf Grimme, "ein Zeitgestalter und zugleich ein Empörer gegen die Zeịt." Der Dichter soll "beileibe also nicht der Registrator der Zeit in ihrem bloßen Da- und So-Sein [sein], vielmehr der, der in ihr das sieht, was werden will und soll, der Seismograph der Tiefenschichten dieser Zeit, der das innere Erbeben dieser Zeit anzeigt. Der Dichter tut den Vorgriff auf die Zukunft und formt entscheidend damit das geistige Gesicht der Zeit, die kommt. Den Zeitgenossen, die nur das Heute sehen und in ihm verharren möchten, ist er darum der ewige Unbequeme. Sie sehen nicht wie er in jeder Zeit das Meta-Zeitliche, das jede Auseinandersetzung mit der Zeit, so wie sie ist, erst sinnvoll macht." 9

Haushofer glaubte, daß der Dichter mit dem Gelehrten und dem Politiker gehen müsse. Dieser Glaube ist in allen seinen Dramen zu spüren.

\footnotetext{
${ }^{8}$ Adolf Grimme. "Albrecht Haushofer, Nach 10 Jahren ein Wort des Gedächtnisses zum 23.4.45, "Die Sammlung: Zeitschrift für Kultur und Erziehung. (10 Jahrgang, 1955), S. 180 .

9Adolf Grimme. "Rufer in die Zeit," in In Memoriam Albrecht Haushofer. (Herausgegeben von Rolf Italiaander). Haumburg: Verlag Friedrich Oetinger, 1948., S. 8.
} 
Immer stellt er Gelehrte, Philosophen und Dichter als Gegenspieler der Politiker und soldaten auf. In dem Drama Scipio ist es der griechische Staatsmann und Historiker Polybios; in Sulla, der Philosoph und Gelehrte Zosias; in Augustus sind es die Dichter Vergilius, Horatius una Catullus; in Die Makedonen der Lehrer und Philosoph Aristoteles und der Philosoph-Priester Amenhotep; und schlieBlich der Dichter und der Mönch in Chinesische Iegende. Die Moabiter Sonette verkörpern dieselbe Idee. Sie erscheint nicht nur in diesem oder jenem Sonett, sondern im gesamten Zyklus. Man darf sagen, daß Haushofer sowohl als Dichter als auch als Lehrer und Wissenschaftler diese Idee verkörpert.

Mit allen Mitteln reiner Wissenschaft hab ich versucht, Erforschliches zu erkennen, das Klare klar, das Dumpie dumpf zu nennen-, hab eignes Denken immer streng gerafft. Hab dann versucht, ins Tätige zu wenden
des Wissens Gabe. 10 In seinen Dramen, die durch die politischen Ereignisse seiner Zeit motiviert wurden, nahm er die Rolle eines Kritikers an, und gleichzeitig wollte er auf der Seite des Verstandes und der Vernunft gegen die gefährlichen Handlungen des verantwortungslosen Regimes kämpfen. Er suchte Bühnen für seine Dramen, und es gelang ihm, sie für Scipio und Augustus und für sein ersten politisches Drama, eine Komödie, Und so wird Pandurien regiert zu fin-

$$
10 \text { Haushofer, Moabiter Sonette, S. } 68 .
$$


den.

Furchtlos und mit Stolz schrieb Haushofer seine Dramen. Wenn er den Dichter Vergilius in Augustus fragen läßt, "Glaubst Du denn im Ernst von mir, ich schriebe nur ein Wort, das ohne Sinn ist, weil ein Mächtiger mich mahnen könnte?", äußert er dieselbe Freiheit, mit der er den Tyrannis seiner Zeit gegenüberstand und seine Dramen zum mahnenden Gewissen werden ließ. 11 Rainer Hildebrandt schreibt, daß Haushofer die Römertrilogie dem "hohen Herrn" mit einer persönlichen Widmung überreicht hätte. 12

Ohne Zweifel erfüllen die Dramen die Anforderungen von politischen Schriften.

Die früheren Gedichte, besonders die Sammlung von 1938, Gastgeschenk, sind voll mahnender und didaktischer Elemente, die charakteristisch für politische Dichtung sind. Aber auch dazu gehört seine pessimistische Grundhaltung. Der Leserspürt immer deutlicher sein Zurückziehen in sich selbst, das so klar aus den Moabiter Sonetten spricht. Obwohl die Themen vieler Gedichte politisch sind, nehmen sie einen persönlichen Ton an, der sie aus dem Bereich politischer Dichtung hebt. Sicher arücken viele der früheren Gedichte den

\footnotetext{
11 Grimme, "Nach 10 Jahren", Die Sammlung, 10 Jahrgang, 1955, s. 180.

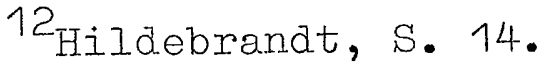


Haß des Dichters gegen den Nationalsozialismus aus, aber man fragt sich, ob Haushofer sie als Oppositionsgedichte in dem Sinn, daß sie Widerstand oder. Gegenhandlung erwecken sollten, beabsichtigte. Da sie nur als Frivataruck und nicht für allgemeine Verbreitung geschrieben wurden, scheint das nicht der Fall gewesen zu sein.

Durch seine Gedichte fand Haushofer für aie innere Hoffnungslosigkeit, an der er litt, eine Befreiung. Nach Hildebrandt waren die Dramen "seine Art der Selbstbefreiung aus seinem gefesselten politischen Gestaltungswillen." 13

In einigen der Moabiter Sonette zeigt es sich-, daß er überzeugt war, daß die Zeit für Opposition vorbei war. Andere weisen darauf hin, daß die Ereignisse außerhalb menschlicher Kontrolle lagen. Er äuBerte diese Ủberzeugung schon lange vor dem Zusammenbruch des nationalsozialistischen Regimes, als er über Hitler sagte: "Er wird seinen Weg ganz zu Ende gehen. Dann wird er verschwinden, und keiner wird wissen, wie er geendet hat."14

Wenn man Charles Hoffmanns Überzeugung als wahr annimmt, daß "the raison d'etre of this verse is not to show others what the Third Reich is nor to arouse their opposition to it, but rather a poetic diary whose entries recall a variety of personal experiences,

$$
\begin{aligned}
& 13 \text { Ibia., S. } 14 . \\
& 14 \text { Ibia., S. } 76 .
\end{aligned}
$$


102

memories and ideas, "15 dann kann man die Moabiter Sonette nicht als "politische Dichtung" bezeichnen. 
IX: DER DICHTERISCHE UND HISTORISCHE WERT DER MOABITER SONETIE

Wegen ihrer Natur und der Umstände, aus denen die Moabiter Sonette entstanden sind, schätzt man sie meistens als ein Zeugnis der inneren deutschen Widerstandsbewegung. Diese Meinung überschattet fast immer eine Abschätzung ihres Wertes als "reine" Dichtung.

Felix Wassemann schreibt, daß die Moabiter Sonette zu den wichtigsten Zeugnissen des geistigen und politischen Widerstands der deutschen Oberschicht gegen das nationalsozialistische Regime gehören... Man möchte sie ein dichterisches Gegenstück zu den Tagebüchern Ulrich von Hassel nennen, ein Denkmal der gleichen Haltung und des gleichen tragisch gescheiterten Versuchs, Deutschland von Hitler zu befreien, bevor es zu spät zum Wideraufbau war. 1

AuBerhalb Deutschlands, und besonders in Amerika Iiegt Haushofer's Ruhm fast nur in den Moabiter Sonetten. Und ebenso werden die Moabiter Sonette innerhalb und auBerhalb Deutschlands hëufig als eines der berühmtesten Zeugnisse der deutschen "inneren Emigration" erkannt. In einer früheren Rezension der Moabiter Sonette schrieb Ursula Teyffrath in Welt und Wort, daß die Sonette "wahrhaft ein Vermächtnis" sind. Sie meint auch, sie sind.

...ein Dokument, das weit über ein bloßes Blutzeugnis aus böser Zeit, Denkmal für einen Märtyrer hinausgeht... Denn die Vornehmheit und sittliche Kraft eines ganzen, nicht antastbaren Menschentums leuchtet aus ihnen, das durch Haft und bemütigende Behandlung nicht zerbrechen, sondern zur letzten

\footnotetext{
Wassermann, Monatsherte, XI, No. 6, (Oktober, 1948), S. 305 .
} 
Entfaltung gebracht mit der entrückten inneren Heiterkeit anheimstellender Gläubigkeit beschenkt wurde.?

In zahlreichen Literaturgeschichten und AutorenLexika findet man den Namen Albrecht Haushofer. Alle erwähnen die Moabiter Sonette als ein wichtiges Zeugnis der deutschen widerstandsbewegung.

Faul Fechter in Geschichte der Deutschen Literatur schreibt, "Der kluge, freundliche Mann machte nie Aufheben von seiner literarischen Arbeit. Vielleicht fügte das Schicksal es gerade darum so, daß sein Name heute durch die letzte dieser Arbeiten weiterlebt." 3

In seinem Werk Deutsche Eichter und Schriftsteller unserer Zeit zitiert Franz Lennartz Karl Jaspers Worte..."[as] stärkste dichterische Zeugnis vom deutschen Widerstand," 4 um die sonette zu kennzeichnen.

Im Handbuch der deutschen Gegenwartsliteratur findet man diese Wertbestimmung: "Seinen Nachruhm verdankt Haushofer den in der letzten Haft entstandenen 79 Moabiter Sonette, einem erschütternden und dichterisch gültigen Zeugnis der deutschen Widerstandsbewegung. " 5

Ursula Teyffrath, Renzension der Moabiter Sonette in Welt und Wort. 1. Jahrgang, Heft 5 (Oktober, 1946) S. 151.

3 Panl Fechter, Geschichte der deutschen Iiteratur. Gütersloh: C. Eertel smann Verlag, $195 \overline{3}$, S. 758.

4 Franz Lennartz, Deutsche Dichter und Schriftsteller unserer Zeit. Stuttgart: Alfred Kroner Verlag, 1959, S. 280.

${ }^{5}$ Dr. Hermann Kunisch. (Herausgeber), Handbuch der deutschen Gegenwartsliteratur. Wiunchen: Nymphenburger Verlagshandlung, $1965,5.257$. 
Man kann es kaum leugnen, daß die Sonette ein gewisses poetisches Niveau erreichen, und daß ihre Langlebigkeit und ihr Erfolg als Gedichte der Widerstandsbewegung darauf zurückzuführen ist.

Zur Zeit ihres erstmaligen Erscheinens erhielten sie zwei interessante Kritiken - eine aus Deutschland und die andere aus Amerika. Ursula Teyffrath charakterisiert die Sonette folgendermaßen:

Nicht spontane Lyrik, überhaupt nicht eigentlich Dichtung sind diese Sonette, sondern in die schwingende Klarheit einer edlen Kultursprache und sicher beherrschten Kunstform gebundenes Gedankengut, worin zu dem tief im Innern bewegten Erleben eine weite Allgemeinbildung, Ankuüpfungspunkte und Vergleichsmöglichkeiten fügt. So sind es Profile und Genrebilder, die das Erlebte und Durchdachte zum Ausdruck bringen. 6

(Man möchte Ursula Teyffrath fragen, was ihre Definition von Dichtung eigentlich ist!)

Die in den Vereinigten Staaten erschienene Kritik von Hermann Salinger gibt den Sonetten als "reine" Lyrik eine negative Beurteilung.

The Moabit sonnets are, nevertheless, in a sense 'required reading:' not as 'pure Poetry' but as a case history. Obviously stemming from the neoclassic tradition and containing more than a strain of Platen (whose perfection they never attain) they gain upon the reader in spite of their monotony. They are undeniably 'sickled o're' by prison pallor, but one feels that Haushofer's poetry vould have smelt of the lamp in any case... In their pseudoclassical posturing, their mystical escape, their hopeless grandezza they are typical of their times.?

\footnotetext{
6 Teyffrath, Welt und Wort, $\mathrm{S} .151$.

7 Hermann Salinger, Review of the Moabiter Sonette, in Monatshefte für deutschen Unterricht, deutsche sprache und Iiteratur. VIII, No. 6 (october, 1946) S. 380 f.
} 
Die Theorien über die Bewertung eines Gedichts sind vielseitig. Das Abtasten der Oberfläche dieser reich-haltigen Iiteratur ginge über das hinaus, was diese Be_ handlung anstrebt. Jedoch gibt es von Helmut Miotekat in seinem Artikel "Vom Wesen des modernen Gedichtes und von den Möglichkeiten der Interpretation, " eine präzise und gültige Abhandlung über den dichterischen wert eines Gedichts. "Die Frage nach dem Wert des modernen Gedichts," schreibt Motekat, "kann daher nur die Frage nach seiner inneren Wahrheit sein und danach ob diese Wahrheit in der Gestalt des Gedichts ihre adäquate und vollkommene Verwirklichung gefunden hat, und zwar im Zusammenwirken aller aufgerufenen Gestaltungselemente." 8

Im Raum dieser Definition versucht dann ein Gedicht eine Erfahrung durch sprachliche Vermittlung mitzuteilen, so daß der Leser die Erfahrung für sich selbst neu zu schaffen vermag. Es soll diesen Zweck durch eine Verwendung der Sprache in solch einer Weise erlangen, daß die sprachlichen und formalen Elemente sich mit dem Inhalt zusammenfügen und wirken. Es wird einem erfolgreichen Gedicht gelingen, eine Übereinstimmung von Satzgefüge und Gedanken, von Personendarstellung, Raum, Metrum, Wortschatz und Aufbau zu erreichen.

Die formalen Schwächen der Moabiter Sonette sind in

${ }^{8}$ Helmut Motekat, "Vom Wesen des modernen Gedichtes: und von den Möglichkeiten der Interpretation, in Interpretationen modernen Iyrik. Berlin und Frankfurt $\overline{a . M .}$ (Verlag Moritz Dieserweg, 1958) s. $15 \mathrm{f}$. 
dieser Arbeit schon erwähnt worden, und sicher erreicht nicht jedes Sonett der Sammlung eine Übereinstimmung von Form und Inhalt. Man soll aber die Umstände nicht vergessen, aus denen die Sonette entstanden sind. Haushofer hatte keine Nöglichkeit, die Sonette umzuschreiben oder zu verbessern; der bloße Besitz von Bleistift und Papier. war während der Gefangenschaft streng verboten. Unter diesen Umständen ist es erstaunlich, daß die Sonette überhaupt solch eine künstlerische Vollkommenheit erreichten.

Ohne Zweifel besitzen die Nioabiter Sonette die innere Wahrheit, über die Motekat schrieb. Ohne diese Wahrheit würden sie niemals eines der wichticsten Zeugnisse des inneren deutschen Widerstandes geworden sein. Hätten sie nur Haushofers eigenen Schmerz, seine eigene Enttäuschung und Bitterkeit, und seinen tiefen Haß gegen das nationalsozialistische Regime wiedergespiegelt, dann würde man sie schon lange vergessen haben. Sie haben aber auch der Bitterkeit, der Enttäuschung, dem Schmerz vieler seiner Iandsleute Ausdruck gegeben. Hier ist eine Abschätzung der Sonette aus dem Handbuch der deutschen Gegenwartsliteratur:

Die Dichtungen Haushofers bezwingen weniger durch sprach-schöpferische Kraft als durch ihre unbedingte Menschlichkeit und geistige Zucht.9

Man muß zugeben, als "reine" IJrik gelten die 
Moabiter Sonette wenig, aber meiner Meinung nach brauchen sie das auch nicht. Ihre Größe besteht nicht darin, daß sie als sonette zu denen ersten Ranges gehören, nicht darin, daß man sie neben die größten deutschen Dichtungen stellen kann. Ihre Größe liegt in ihrer unbedingten Menschlichkeit. Noch heute leben sie als Symbol des Widerstandes gegen ein böses Regime. Der Geist der Männer dieser Widerstandsbewegung hat eine dichterische Verkörperung in diesen sonetten gefunden. Aber auch der Geist des Menschen Albrecht Haushofer lebt in aen Moabiter Sonetten weiter. Der Geist, der ihn zu philosophischer Überwindung des Lebens und des Todes führte, ist das "Andre", das er meinte, als er die Worte aus Scipio schrieb:

"Mit feiger Tat könnt Ihr den Körper treffen! Da.s Andre nie."10

Die Moabiter Sonette bleiben das "Andre", das Immer-weiter-Wirkende, das die Frist des Menschenlebens weit überlebt. 
Künstlerische Werke Albrecht Haushofers

Abend in Herbst. (Unveröffentlichtes Manuskript.)

Das Drama wurde von Eva Preiß in ihrer

Dissertation, "Albrecht Haushofer: Ein

Versuch einer Monologie," Wien, 1957 eingeschossen.

Augustus, Ein Schauspiel in fünf Akten. Berlin: Fropyläen Verlag, 1939.

Chinesische Legende: Eine dramatische Dichtung. Berlin: Lothar Blanvalet Verlag, 1949.

Die Makedonen. (Unveröffentlichtes Manuskript.)

Gastgeschenk. Privatdruck, 1938.

Moabiter Sonette. Berlin: Lothar Blanvalet Verlag, 1946.

Richtfeuer. Privatdruck, 1932.

Scipio, Ein Schauspiel in fünf Akten. Berlin: Propyläen Verlag, 1934

Sulla, Ein Schauspiel in fünf Akten. Berlin: Propyläen Verlag, 1938.

Und so wird in Pandurien regiert, Eine politische Komódie. Privatdruck, 1932. (Unter dem. pseudoname, Jurgen Dax.)

\section{Sekundäre Literatur}

Becher, Johannes, R. Das poetische Prinzip. Berlin: Aufbau Verlag, 1957.

Blankenagel, John C. "Albrecht Haushofer's Moabiter Sonette," German Quarterly, XX., No. 3 (Nay, 1947), $189-194$. 
Das Gewissen entscheidet, Bereiche des deutschen Widerstands von $1933-1945$ in Iebenbildern. (Herausgegeben von Annedore Leber in Zusammenarbeit mit Willy Brandt und Karl Dietrich Bracher.) Berlin: Mosiah Verlag, 1957.

Fechter, Paul. Geschichte der deutschen Iiteratur. Gütersloh: C. Bertelsmann Verlag, 1953.

Freidman, Norman and McIaughlin, Charles A. Poetry: An Introduction to its Form and Art. New York, Evanston and London: Harper \& Row, 1963.

Grimme, Adolf. "Albrecht Haushofer, Nach 10 Jahren ein Wort des Gedächtnisses zum 23.4.45," Die Sammlung: Zeitschrift für Kultur und Erziehung. 10 Jahrgang, 1955, 179 - 182 .

Grimme, Adolf. "Rufer in die Zeit," in In Memoriam Albrecht Haushofer. (Herausgegeben von Rolf Italiaander). Hamburg: Verlag Friedrich Oetinger, 1948.

Gudehus, Eva Maria. "Albrecht Haushofers 'Moabiter Sonette' (Eine Untersuchung nach Inhalt und Form)," Wissenschaftliche Hausarbeit zum Staatsexamen, Dresden, 1964. (Maschine geschrieben.)

Hassel, Ulrich von. Vom anderen Deutschland, Aus den nachgelassenen Tagebüchern $1938-1944$. Zirich und Freiburg: Atlantis Verlag, 1946.

Faushofer, Heinz. "Souvenirs sur mon frère AIbrecht," Verger. Revue des Spectacles et des Lettres en Allemagne occupee. 1. Jahrgang, No. 5 . (Kein Datum), $23-26$.

Haushofer, Heinz. Persönliches Gespräch. Hartschimmelhof, den 4. März 1967.

Heimpel, Hermann. Die halbe Violine. Eine Jugend in der Residenzstadt München. Stuttgard: K.F. Koehler Verlag, 1949.

Hildebrandt, Rainer. Wir sind die Letzten. Aus dem Leben des Widerstandskëmpfers Albrecht Haushofer und seiner Freunde. Neuwied/Berlin: Michael Verlag, 1949. 
Hobart, Michael. "Ies nouveaux masques de la mort et le lyrisme allemand contemporain: Albrecht Haushofer's 'Moabiter Sonette' et Rudolf Hagelstange's 'Ballade vom verschütteten Leben'," Critique: Revue générale des Publications francaises et étrangeres. IX, No. 77 (October, 1953), $837-852$.

Hoffmann, Charles. Opposition Poetry in Nazi Germany. Berkeley and Los Angeles: University of California Publications in Modern Philology, University of California Press, 1962.

Ibel, Rudolf. Gestalt und Wirklichkeit des Gedichtes. Passau: bei Heimeran, Gesamtherstellung Passavia, 1964.

Italiaander, Rolf. Besiegeltes Iében. Begegnungen auf vollendeten Wegen, Gerhart Hauptmann, Ulrich von Hassel und Albrecht Haushofer. Goslar: Volksbücherei Verlag, 1949.

Kunisch, Hermann Dr. (Herausgeber) Handbuch der deutschen Gegenwartsliteratur. Munchen: Nymphenburger VerlaghandIung, 1965.

Lehmann, Wilhelm. Kunst des Gedichtes. Frankfurt am Main: Insel-Verlag, 1961.

Iennartz, Franz. Deutsche Dichter und Schriftsteller unserer Zeit. Stuttgart: Alfred Kröner Verlag, 1959.

Modekat, Helmut. "Vom Wesen des modernen Gedichtes und von den Möglichkeiten der Interpretation," in Interpretationen moderner Ifyrik. Berlin und Frankfurt a. Main: Verlag Moritz Diesterweg, 1958.

Mönch, Walter. Das Sonett, Gestalt und Geschichte. Heidelberg: F.H. Kerle Verlag, 1955.

Nobècourt, Jacques. "A la trace d'Albrecht Haushofer," Verger: Revue des Spectacles et des Iettres en allemagne occupée. 1. Jahrgang, No. 5 (Kein Datum) $6-13$. 
Preiß, Eva. "Albrecht Haushofer. Ein Versuch einer Monologie," Dissertation, Wien, 1957. (Maschine geschrieben.) Rébertat, Jacques.
et traduction)
Sonnets de Moabit (Avant-propos
Paris: Pierre Seghers. 1954.

Salinger, Herman. Review of the Moabiter Sonette in Monatshefte für deutschen Unterricht, deutsche Sprache und Iiteratur. XXXVIII, No. I (October, 1946) $380-381$.

Staiger, Emil. Die Kunst der Interpretation: Studien zur deutschen literaturgeschichte. Zürich: Atlantis Verlag, 1957 .

Stubbe, Walter. "Seinen Gedanken," in In Memoriam Albrecht Eaushofer. (Herausgegeben von Rolf Italiaander), Hamburg: Verlag Friedrich Oetinger, 1948.

Teyferath, Ursula. Review der Moabiter Sonette, in Welt und Wort. 1. Jahrgang, Heft 5 (Oktober, 1946), $151-152$.

Wassermann, Felix M. "Ein unbekanntes Denkmal deutscher Dichtung in der Krisenzeit der DreiBiger Jahre des XX. Jahrhunderte: Zwanzig Gedichte Albrecht Haushofers," The Journal of English and Germanic Philology, IV, No. 1 (January, 1956), $27-34$.

Wassermann, Felix M. "Macht und Geist in Albrecht Haushofers Römerdramen, " Nonatshefte für deutschen Unterricht, deutsche Sprache und Iiteratur. XIVI, No. 4 (April/May, 1954), $\overline{312-324}$.

Wassermann, Felix M. "Albrecht Haushofers Chinesische Legende," Monatshefte für deutschen Unterricht, deutsche sprache und literatur. XIII, No. ? (November, 1950), $317-320$.

Wassermann, Felix M. "Ein Denkmal des Fiwigen Deutschlands: Albrecht Haushofers 'Moabiter Sonette'," Monatshefte für deutschen. Unterricht, deutsche Sprache und Iiteratur. XI, No. 6 (Oktober, 1948) $305-313$.

Wehrli, Max。 Wert und Unwert in der Dichtung. Köhl und Olten: Verlag Jakob Hegner, 1965. 
Weizsäcker, Carl F. von. "Albrecht Haushofer und die Jugend," in In Niemoriam Albrecht Fiaushofer. (Herausgegeben von Rolf Italiaander) Hamburg: Verlag Friedrich Oetinger, 1948.

Zellner, w. Miüchner Merkur. 27. Mai 1953.

Zucker, A.E. "The literary Work of Albrecht Haushofer," Viodern Language Quarterly, XI, No. 4 (December, 1950) 462-471. 